\title{
Perceptions of Equity and the Distribution of Income
}

\author{
Julio J. Rotemberg, Harvard University
}

This article develops a model in which quit rates, and thus the income distribution, depend on employee perceptions of the accuracy of employer assessments of individual productivity because these latter assessments affect wages. When employees believe that these assessments are accurate, income inequality tends to be high. The model can account for the negative correlation across some countries of inequality and the extent to which inequality is deemed to be excessive. It also fits the contrast in U.S. and French experiences concerning the tenure of highly educated workers with high wages relative to the tenure of lower-paid workers.

People have opinions about the degree to which differences in pay reflect differences in productivity or are, instead, the result of favoritism, personal connections, and the whimsy of people with influence. In this article, I show that opinions of this sort can matter a great deal. In particular, I demonstrate that opinions about the extent to which people believe that differences in pay reflect differences in individual productivity

I am very grateful to Mauro Guillen, Frank Levy, Mancur Olson, and Michael Woodford and to the participants at seminars at Columbia, Harvard, Johns Hopkins, the National Bureau of Economic Research, and the University of Maryland for helpful suggestions. I also wish to thank Hank Farber and Dan Feenberg for help with the Current Population Survey, Francis Kramarz for providing me with data that he obtained by processing the Enquète Emploi, and the National Science Foundation and the Harvard Business School Division of Research for research support.

[Journal of Labor Economics, 2002, vol. 20, no. 2, pt. 1]

(C) 2002 by The University of Chicago. All rights reserved. 0734-306X/2002/2002-0003\$10.00 
can affect the actual distribution of income even when they have no effect on individual marginal products. ${ }^{1}$

My focus on the effects of these beliefs raises the question of where these beliefs come from. In particular, there is the issue of whether one should not simply assume that people know the truth so that there is no difference between beliefs about the connection between income and productivity and the actual connection between these variables. In this article, I allow the actual and the perceived connections to differ, and I do this for two reasons.

First, the truth about the connection between pay and productivity is difficult to know. If one leaves aside the possibility of experimenting by varying one's own productivity, it is very hard to learn about this connection unless one actually observes the output of different people. ${ }^{2}$ But, in modern industrial firms where workers are extremely interdependent and where the aggregate value produced by the firm is subject to large random disturbances, measuring the output of individuals is very hard. There are, of course, indirect measurements of the relationship between productivity and pay. Under the assumptions of the stripped-down model I present, for instance, this relationship can be inferred from the statistical properties of individual wages. However, the extent to which statistics of this sort shed light on the issue depends on auxiliary assumptions, the validity of which is itself difficult to establish empirically.

A second and related reason to consider models where the perceived connection between pay and productivity differs from the actual one is that people do not appear to agree on this connection. A particularly telling set of examples of this disagreement can be found in Hochschild (1981), who reports on 28 in-depth interviews about the distribution of resources. Summarizing, she says (p. 140), "The poor ... often argue that if productivity were truly rewarded, this would create more equal incomes (emphasis in original)." And she goes on to say (p. 141), "On the other hand, wealthy respondents ... often argue that if productivity were truly rewarded, this would create less equal incomes." ${ }^{3}$

\footnotetext{
${ }^{1}$ The article is closely related to Piketty (1995), where changes in the perceived connection between effort and income change the equilibrium level of effort and thus change actual income. The difference is that, in Piketty (1995), these changed beliefs affect actual income only by first affecting the potential productivity of individuals.

${ }^{2}$ This, too, is closely related to Piketty's (1995) argument that it is difficult to learn the connection between effort and pay.

${ }^{3}$ These differences are consistent with those found in larger surveys. McClosky and Zaller (1984) report that $84 \%$ of respondents whose family income is above $\$ 35,000$ view the capitalist system as fair and efficient, while only $51 \%$ of respondents with an income below $\$ 35,000$ do so. This type of statement may simply reflect different tastes for redistribution, but it also could reflect differences in opinions about the determinants of individual incomes.
} 
The difficulties in determining individual output do not stop firms from basing their pay on estimates of this output. Indeed, in the case of a frictionless competitive labor market, the wage of an individual is equal to his employer's estimate of his marginal product. Opinions about whether people are or are not paid their marginal product do not alter this, so they have no effect on the actual distribution of income.

In the model I present, these opinions matter because I depart from the assumptions of the standard competitive labor market in two ways. First, I suppose that a worker's departure from a firm depends on his outside opportunities and that the firm has imperfect information about these opportunities. The result is that employers have some monopsony power and that wages depend both on the firm's perception of their employees' marginal products and on the firm's assessment of the likelihood that these employees will leave. Second, there are search costs, so workers have to form an opinion about what they will be paid on the outside before they leave a firm.

This combination of assumptions yields a simple mechanism by which opinions affect the distribution of income. If workers regard the evaluations of their employers as inaccurate, they are tempted to quit if they receive a low evaluation, while they are inclined to stay if they receive a favorable one. The reason is that, if firms are inaccurate in their evaluations, it is good to work for a firm that has an inaccurately high estimate of one's own ability. Employees who receive high ratings from their current employers conclude that they have found a good match, while those who receive a low rating expect alternate employers to pay higher wages.

Thus, if workers change their minds and come to see firms as being more accurate, they change their quitting behavior. Workers who receive a low rating from their firm become more predisposed toward staying (because they now expect a low rating from other firms as well). A rational monopsonistic firm would then tend to cut their wages. Similarly, this change in perception leads workers who have gotten a high rating to become more prone to quit because their fear of getting low wages from alternate employers is reduced. This, in turn, tends to raise their wages. Since the wages of highly rated employees rise while those of employees with low ratings fall, inequality increases.

The article proceeds as follows. Section I presents the model and studies how the wage distribution changes in response to changed perceptions by workers of the accuracy of firm's evaluations. Section II studies the change in aggregate output when workers come to perceive firms as more accurate. One difficulty with evaluating aggregate outcomes is that one needs an "objective" measure of firms' ability to evaluate workers and, for the reasons I mentioned, it is hard to know how one would go about obtaining one. For the purpose at hand, I pretend that firms have an accurate assessment of their own ability to judge individuals' productivity. 
This leads me to use the firms' estimates of their accuracy in computing the model's predictions regarding aggregate output.

The main conclusion of this section is that there are plausible conditions under which aggregate output declines when workers deem firms to be more accurate, though there also exist conditions under which output rises. One reason for output to decline is that increased confidence in the ability of firms to evaluate workers leads more high-wage workers to quit and there is often a larger deadweight loss associated with these quits than there is with the quits of low-wage workers.

Section III discusses the empirical relevance of the model. Beliefs about the fairness of the distribution of income differ both cross-sectionally and over time. In particular, residents of different countries harbor different beliefs about this fairness. I thus study the connection between the income distribution in individual nations and the beliefs held in those nations. I show that, across a sample of seven countries, actual inequality is negatively correlated with the perception that income inequality is excessive. This is in broad accordance with the predictions of my model.

It also may be possible for beliefs about the fairness of the income distribution to change fairly rapidly within a country. This could occur as a result of the spreading of incontrovertible new evidence (as in Bolton and Harris 1999), but it might also happen in cases where the "new" evidence is relatively tenuous. The perception that inequality is excessive is presumably associated with voting for candidates who favor redistribution. Thus, changes in the dominant political discourse can to some extent be read as changes in the degree to which individuals see unequal outcomes as fair. The model would then be able to account for the fact that income inequality has increased disproportionately in countries such as the United States and the United Kingdom where the political support for redistribution appears to have waned.

Since the implications of the model for the distribution of income are closely tied to its implications for quits, it seems worthwhile to compare the changes in job tenure across countries that have experienced different changes in their income distributions. I thus study changes in job tenure in France and the United States. According to the model, job tenure among those with relatively high incomes should have fallen in the United States relative to the tenure of lower-wage individuals (as it is the willingness to hop from job to job among high-wage individuals that has raised their wages). By contrast, in France, job tenure among individuals with high incomes should not have fallen relative to that of individuals with low incomes. The actual changes in the tenure of individuals with relatively high levels of education are consistent with these implications, though this is not true for individuals whose educational attainment is lower. Section IV concludes. 


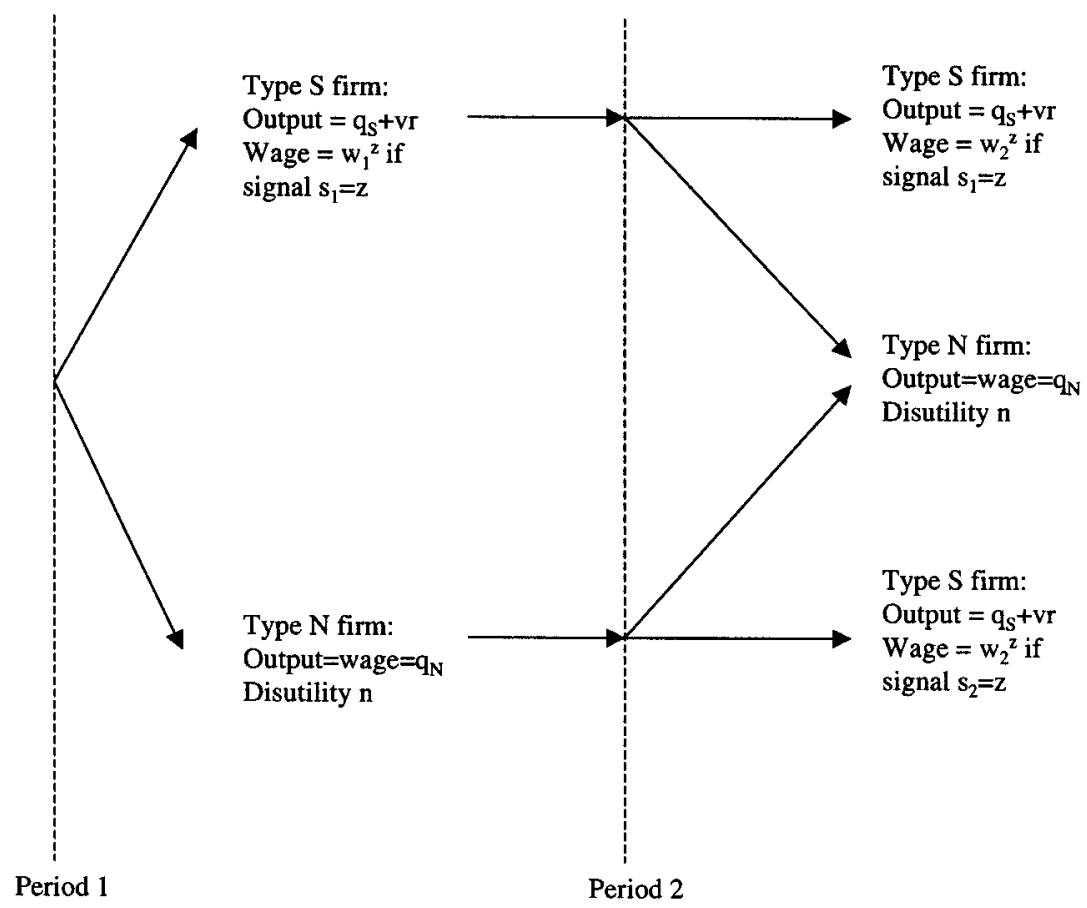

Fig. 1.-The sequence of potential employers

\section{The Model}

\section{A. The Basic Structure}

Employees are of two types. I suppose that those for whom a parameter $r$ is equal to one have higher productivity, at least in certain occupations, than those for whom the parameter $r$ is equal to zero. While firms do not observe $r$ directly, they do observe signals that are correlated with $r$. The focus of my study is the connection among wages, employee turnover, and employee beliefs about the accuracy of firms' signals about $r$.

There are two periods because this is the minimal number of periods required to study turnover and my model is one where beliefs affect wages only through their effect on the tendency to quit. The sequence of potential employers for each employee is depicted in figure 1. In each period, employees choose whether to work at a firm of type $S$, where their output equals $q_{S}+v r$ with $v>0$, or whether to work at a firm of type $N$, where employee output is independent of $r$. Individuals start the first period attached to particular firms of type $S$ in the sense that, for each employee, there exists a firm that observes a signal $s_{1}$ that is correlated with the employee's productivity. This firm makes a wage offer to the employee 
at the beginning of period 1. Simultaneously, the employee receives an offer from a type $N$ firm. The employee then chooses which firm he wants to work for in period 1.

If he works for the firm of type $N$ in period 1, there is a second type $S$ firm that observes a new signal $s_{2}$ about the employee's productivity at the beginning of period 2. This employee then receives two wage offers in period 2, one from this new type $S$ firm and one from a new type $N$ firm. If, by contrast, the employee stays with his initial type $S$ firm in period 1, no other type $S$ firm offers him a job in period 2 . Such an employee must thus decide in period 2 whether to accept the new wage offer that he receives from his initial type $S$ firm or to accept an offer made by a new type $N$ firm. This captures two aspects of quitting a job. The first is that departure from a job often expands an employee's range of opportunities. The second is that the opportunities that will become available are somewhat uncertain at the time the individual quits.

The offers from firms of type $N$ play a dual role in my analysis. On the one hand, they dampen the monopsony power of the type $S$ firms, and this is indeed their only role in period 2. In addition, they serve as transitional jobs for employees who wish to move from one type $S$ employer to another. To keep the analysis simple, I suppose that firms of type $N$ pay employees the value of their marginal product $q_{N}$ while also conferring on to them a nonpecuniary utility that is equivalent to an additional compensation of $n .{ }^{4}$ Abusing the language somewhat, I thus treat the employee as receiving a total compensation of $q_{N}+n$. For any given employee, the value of $n$ is drawn independently at each point in time from a distribution whose cumulative density function is $F(n)$ with $0 \leq n \leq \bar{n} .^{5}$

There is another interpretation for $n$ that yields similar results for the behavior of wages and quitting decisions. Instead of being thought of as a nonpecuniary benefit of working at a firm of type $N, n$ can be thought of as a nonpecuniary cost of working at a firm of type $S$. One can imagine that, at the beginning of each period, the employer of type $S$ assigns a particular task to the employee and that this gives him a disutility of $n$. The analysis of equilibrium wages in the second period is then unchanged as long as the level of this disutility is unknown to the employer of type

\footnotetext{
${ }^{4}$ The simplest rationalization for this is that there are actually two alternative firms in which the individual has a productivity $q_{N}$ and that the employee gets the same nonpecuniary utility in both. If each of these firms gets to make one wage offer to the employee, then the logic of Bertrand competition leads them to offer him $q_{N}$.

${ }^{5}$ Using zero as the lower bound for the realizations of $n$ does not reduce the generality of the analysis, since one can think of the lowest value for $n$ as being incorporated in $q_{N}$.
} 
S. First-period wages are not the same, but respond in a similar way to changes in employee beliefs.

I analyze the model backward starting with the wages paid in the second period at firms of type $S$. I then study expected compensation in the second period as viewed from period 1 . This differs from expected wages at $S$ because individuals have the option of working in firms of type $N$. Finally, the final subsection describes equilibrium wages in the first period.

\section{B. Second-Period Wages}

Employers in type $S$ firms know that employees will leave and go to type $N$ firms if they are offered a wage $w$ that is lower than the employee's realization of $q_{N}+n$ (or, equivalently, if $q_{N}$ exceeds the realization of $w-n)$. The expected benefit from keeping an employee to which the firm pays $w$ is $\left(q_{s}+v E r-w\right)$, where $E r$ represents the firm's expectation of the employee's $r$. Thus, these employers set their wage offers $w$ to maximize

$$
F\left(w-q_{N}\right)\left(q_{s}+v E r-w\right)
$$

where $E$ takes expectations conditional on the information available to the firm.

The first-order condition for this problem is

$$
f\left(w^{*}-q_{N}\right)\left(q_{S}+v E r-w^{*}\right)-F\left(w^{*}-q_{N}\right)=0 .
$$

This represents the optimum wage as long as the boundary conditions

$$
\begin{aligned}
& f(0)\left(q_{S}-q_{N}+v E r\right)>0 \\
& f\left(q_{N}+\bar{n}\right)\left(q_{S}-q_{N}-\bar{n}+v E r\right)<1
\end{aligned}
$$

and the second-order condition

$$
f^{\prime}\left(q_{s}+v E r-w^{*}\right)-2 f<0
$$

are satisfied. I assume that $f(0)$ is positive and that, for all workers,

$$
q_{s}-q_{N}+v E r>0,
$$

which ensures that the first boundary condition holds, so that $\left(q_{s}+\right.$ $\left.v E r-w^{*}\right)$ is positive in equilibrium and the firm earns positive rents on employees who stay. If the rents $\left(q_{S}-q_{N}+v E r-\bar{n}\right)$ are sufficiently large, the second boundary condition in (3) is violated, and the firm simply pays $q_{N}+\bar{n}$, which ensures that the employee stays with probability one. 
Turning back to the interior case, differentiating (2) with respect to $E r$, $q_{N}$, and $w^{*}$, one obtains

$$
\begin{aligned}
d w^{*}= & \frac{f}{2 f-f^{\prime}\left(q_{S}+v E r-w^{*}\right)} v d E r \\
& +\frac{f-f^{\prime}\left(q_{S}+v E r-w^{*}\right)}{\left.2 f-f^{\prime} q_{S}+v E r-w^{*}\right)} d q_{N} .
\end{aligned}
$$

The second-order condition (4) implies that the denominator in these expressions is positive, so that an increase in the employee's expected productivity $r$ raises the wage offer. To ensure that increases in the employee's outside wage, $q_{N}$, also raise the firm's wage offer, it is necessary and sufficient that

$$
f^{\prime}\left(q_{s}+v E r-w^{*}\right)-f<0,
$$

which is consistent with (4) but puts an even tighter bound on the extent to which $f^{\prime}$ is positive. This bound is needed because an increase in $q_{N}$ lowers the value of $n$ at which individuals depart for a given wage. If $f$ is increasing in $n$, an increase in $q_{N}$ lowers the extent to which increases in $w$ promote employee retention, and this tends to reduce the optimal wage. Given (2), (7) is satisfied as long as $f^{\prime} / F-f^{2} / F^{2}$ is negative. This, in turn, is satisfied if and only if the hazard $f / F$ (which is the hazard of increased departures due to reductions in $n$ ) decreases as $n$ rises. I assume this monotone hazard condition from now on.

To compute the optimal wage, one must know the value of Er. For simplicity, I assume that $s_{1}$ and $s_{2}$ are the only sources of information about $r$ used by firms. In particular, firms whose employees join them in period 2 ignore the work histories of these employees in computing $E r$. This is so even though such firms ought to recognize that employees who left their period-1 employers have, on average, drawn different values of $s_{1}$ than those that did not. The simplest rationalization for this is to suppose that period-2 employers do not believe that the signals observed by these earlier employers are informative. ${ }^{6}$ In an earlier version of this article, I imagined instead that they computed $E r$ under the assumption that they regarded these signals as informative. While this complicates the analysis considerably, it neither changes the results nor contributes much additional insight.

Along similar lines, I suppose that the work carried out by employees

${ }^{6}$ It may also be possible to rationalize such an assumption by embedding this model into one where there are overlapping generations of workers and firms do not know the age of their employees. In such an extended model, however, the quality of the pool of unattached workers is likely to depend on firms' wage policies, as in Acemoglu and Pischke (1996), and I ignore this in my analysis. 
during period 1 does not lead their own employers to acquire additional information about their productivity. Again, the main reason for this assumption is the extra simplicity it brings, though the assumption can be justified by supposing that the firm's only additional information is an indicator of total output that contains negligible information about individual contributions. ${ }^{7}$ Alternatively, one can imagine that the value of the employee's output accrues over time and that the effect on firm output of employees of different productivities is not detected until much after the employees have left the firm.

I now turn to the characteristics of the signals $s_{1}$ and $s_{2}$. I let the unconditional probability that $s_{1}\left(\right.$ or $\left.s_{2}\right)$ is equal to one as well as the unconditional probability that $r$ is equal to one be equal to $\phi$. Thus $\phi$ denotes both the fraction of high productivity individuals and the fractions of individuals who get high signals.

Consider now the beliefs concerning the likelihood that $s_{1}\left(\right.$ or $s_{2}$ ) equals a particular value as a function of the value taken by $r$. It is important to stress that these are subjective beliefs concerning the accuracy of a signal. Thus, these beliefs can differ across agents. I therefore denote by $\sigma$ and $\sigma_{w}$, respectively, the subjective conditional probabilities held by firms and workers that $s_{1}$ (or $s_{2}$ ) equals one conditional on $r$ being equal to one. To ensure that the signals are regarded as informative about $r$, I assume that both $\sigma$ and $\sigma_{w}$ exceed $\phi$.

I let $r^{z}$ denote the subjective probability of firms that $r$ is equal to one given that $s_{1}\left(\right.$ or $\left.s_{2}\right)$ is equal to $z$. This also equals their conditional expectation of $r$. These conditional probabilities are

$$
\begin{aligned}
& r^{1} \equiv P\left(r=1 \mid s_{1}=1\right)=\frac{P\left(s_{1}=1 \mid r=1\right) P(r=1)}{P\left(s_{1}=1\right)}=\sigma \\
& r^{0} \equiv P\left(r=1 \mid s_{1}=0\right)=\frac{P\left(s_{1}=0 \mid r=1\right) P(r=1)}{P\left(s_{1}=0\right)}=\frac{(1-\sigma) \phi}{1-\phi} .
\end{aligned}
$$

Letting $w_{2}^{z}$ denote the wage paid in the second period by type $S$ employers to employees whose $s_{1}\left(\right.$ or $\left.s_{2}\right)$ is equal to $z$, this implies the following proposition.

Proposition 1. $w_{2}^{1}>w_{2}^{0}$.

Proof. Because $\sigma$ exceeds $\phi$, (8) and (9) imply that $E r$ (which equals $\left.r^{z}\right)$ is larger when the signal is equal to one. Given (6), this implies that the wage is higher as well. Q.E.D.

At the same time:

Proposition 2. $w_{2}^{1}-w_{2}^{0}<v\left(r^{1}-r^{0}\right)$.

${ }^{7}$ Even if such an indicator contained good information about average productivity, this would not be very useful if economies of scale obliged the firm to hire many employees of independent ability. 
Proof. Using (2) in (6),

$$
\frac{d w^{*}}{d E r}=\frac{f}{f+\left(f-\frac{f^{\prime} F}{f}\right)} .
$$

Since the term in parentheses is positive, this is smaller than one. This immediately implies the result. Q.E.D.

Thus, while employees with $s_{1}=1$ receive higher wage offers than employees with $s_{1}=0$, the difference between an employee's expected productivity and his wage is also increasing in the value of $s_{1}$.

\section{The Expectation of Second-Period Compensation in Period 1}

I suppose that each individual worker knows the signal $s_{1}$ that is observed by his original type $S$ employer. ${ }^{8}$ Supposing $n$ is the nonpecuniary compensation in a firm of type $N$, an employee with $s_{1}=z$ who stays with his original employer can expect to earn $w_{2}^{z}$ if $q_{N}+n$ turns out to be less than $w_{2}^{z}$. Otherwise he earns $q_{N}+n$. Thus, such an employee can expect to earn $c_{2}^{z}$ in the second period, where

$$
\begin{aligned}
c_{2}^{z} & =F\left(w_{2}^{z}-q_{N}\right) w_{2}^{z}+\int_{w_{2}^{z}-q_{N}}^{\bar{n}}\left(q_{N}+n\right) d F(n) \\
& =q_{N}+F\left(w_{2}^{z}-q_{N}\right)\left(w_{2}^{z}-q_{N}\right)+\int_{w_{2}^{z}-q_{N}}^{\bar{n}} n d F(n) .
\end{aligned}
$$

The derivative of $c_{2}^{z}$ with respect to $w_{2}^{z}$ is the probability of earning this wage, $F\left(w_{2}^{z}-q_{N}\right)$. Because this is positive, proposition 1 implies that the expected compensation of an employee whose $s_{1}$ equals one exceeds that of an employee whose $s_{1}$ equals zero. However, because this derivative is less than one, expected compensation does not rise as fast as this wage

${ }^{8}$ Alternatively, one can assume that he has to infer his $s_{1}$, and thus his secondperiod wage at both his current and alternate type $S$ firm, from his first-period wage. This gives the same equilibrium allocation as in the case where the employee observes $s_{1}$ directly as long as employees with different values for $s_{1}$ get different first-period wages. What complicates the analysis of this case is that the firm can now choose to pay all employees the same first-period wage so as to make it impossible for them to learn their realization of $s_{1}$. In numerical simulations I have carried out, I have not found any parameter combinations for which the firm would profit from this concealment of information. Thus, for the parameters I have studied, the equilibrium is the same whether employees observe $s_{1}$ directly or not. 
offer. The reason, of course, is that individuals who receive low wage offers are more likely to leave their type $S$ employer. ${ }^{9}$

Consider now the expected compensation of an employee who leaves his initial type $S$ employer. If this employee draws a signal $s_{2}$ equal to $z$ at his new type $S$ employer in period 2, he can expect to receive a compensation of $c_{2}^{z}$. This means that his expected period-2 compensation is

$$
c_{L}^{z}=P_{w}\left(s_{2}=0 \mid s_{1}=z\right) c_{2}^{0}+P_{w}\left(s_{2}=1 \mid s_{1}=z\right) c_{2}^{1},
$$

where $P_{w}$ represents employees' subjective probabilities. This compensation depends crucially on the conditional distribution of $s_{2}$ given $s_{1}$. I calculate this under the additional assumption that everyone agrees that the realization of $s_{2}$ is independent of the realization of $s_{1}$ once one conditions on the true value of $r$. In other words,

$$
P\left(s_{2}=1 \mid s_{1}=j, r=k\right)=P\left(s_{2}=1 \mid r=k\right),
$$

where $\mathrm{k}, \mathrm{j}=0,1$.

The worker's subjective probability that a signal $s_{1}$ equal to one will be followed by an $s_{2}$ equal to one is then

$$
\begin{aligned}
P_{w}\left(s_{2}=1 \mid s_{1}=1\right)= & P_{w}\left(s_{2}=1, r=0 \mid s_{1}=1\right) \\
& +P_{w}\left(s_{2}=1, r=1 \mid s_{1}=1\right) \\
= & P_{w}\left(s_{2}=1 \mid s_{1}=1, r=0\right) P_{w}\left(r=0 \mid s_{1}=1\right) \\
& +P_{w}\left(s_{2}=1 \mid s_{1}=1, r=1\right) P_{w}\left(r=1 \mid s_{1}=1\right) \\
= & \frac{\left(1-\sigma_{w}\right)^{2} \phi+\sigma_{w}^{2}(1-\phi)}{1-\phi}=\phi+\frac{\left(\sigma_{w}-\phi\right)^{2}}{1-\phi} .
\end{aligned}
$$

${ }^{9}$ Consider, instead, the case where $n$ is the disutility of working at the type $S$ firm. The employee then earns $w_{2}^{z}-n$ for $n$ below $w_{2}^{z}-q_{N}$ and $q_{N}$ otherwise. Thus, his expected compensation is $q_{N}+F\left(w_{2}^{z}-q_{N}\right)\left(w_{2}^{z}-q_{N}\right)-\int_{0}^{w_{2}^{z}-q_{N}} n d F(n)$. This differs from the value in (11) only by the average value of $n, \int_{0}^{n} n d F(n)$, which is a constant independent of $w_{2}^{z}$. Because only the properties of the connection between expected compensation and the second-period wage matter for the comparative statics concerning how first-period wages and turnover respond to $\sigma_{w}$, these comparative statics carry over to this case as well. 
Similarly, the subjective probability that $s_{2}$ will equal zero given that $s_{1}$ equals zero is

$$
\begin{aligned}
P_{w}\left(s_{2}=\right. & \left.0 \mid s_{1}=0\right)=P_{w}\left(s_{2}=0, r=0 \mid s_{1}=0\right) \\
& +P_{w}\left(s_{2}=0, r=1 \mid s_{1}=0\right) \\
= & P_{w}\left(s_{2}=0 \mid s_{1}=0, r=0\right) P_{w}\left(r=0 \mid s_{1}=0\right) \\
& +P_{w}\left(s_{2}=0 \mid s_{1}=0, r=1\right) P_{w}\left(r=1 \mid s_{1}=0\right) \\
= & {\left[1-\frac{\phi\left(1-\sigma_{w}\right)}{1-\phi}\right]^{2}+\frac{\phi\left(1-\sigma_{)}^{2}\right.}{1-\phi}=1-\phi+\phi\left(\frac{\sigma_{w}-\phi}{1-\phi}\right)^{2} . }
\end{aligned}
$$

Both the expression in (14) and that in (15) are increasing in $\sigma_{w}$ (assuming the signal is seen as informative so that $\sigma_{w}$ exceeds $\phi$ ). The intuitive reason for this is that a higher $\sigma_{w}$ implies that both $s_{1}$ and $s_{2}$ are seen as more highly correlated with $r$. As a result, a higher $\sigma_{w}$ ensures that $s_{1}$ and $s_{2}$ are more highly correlated with each other.

Using (12), this implies that expected compensation for employees who leave with $s_{1}$ equal to zero and one are, respectively,

$$
\begin{aligned}
c_{L}^{0} & =P_{w}\left(s_{2}=0 \mid s_{1}=0\right) c_{2}^{0}+\left[1-P_{w}\left(s_{2}=0 \mid s_{1}=0\right)\right] c_{2}^{1} \\
& =c_{2}^{0}+\phi\left[1-\left(\frac{\sigma_{w}-\phi}{1-\phi}\right)^{2}\right]\left(c_{2}^{1}-c_{2}^{0}\right) . \\
c_{L}^{1} & =\left[1-P_{w}\left(s_{2}=1 \mid s_{1}=1\right)\right] c_{2}^{0}+P_{w}\left(s_{2}=1 \mid s_{1}=1\right) c_{2}^{1} \\
& =c_{2}^{0}+\left[\phi+\frac{\left(\sigma_{w}-\phi\right)^{2}}{1-\phi}\right]\left(c_{2}^{1}-c_{2}^{0}\right) .
\end{aligned}
$$

This implies immediately:

Proposition 3. An increase in $\sigma_{w}$ raises $c_{L}^{1}$ and lowers $c_{L}^{0}$.

Proof. Differentiating (16) and (17),

$$
\frac{d c_{L}^{1}}{d \sigma_{w}}=-\frac{1-\phi}{\phi} \frac{d c_{L}^{0}}{d \sigma_{w}}=2 \frac{\sigma_{w}-\phi}{1-\phi}\left(c_{2}^{1}-c_{2}^{0}\right) .
$$

This is positive because $\sigma_{w}>\phi$ and because the discussion below proposition 1 implies that $c_{2}^{1}$ exceeds $c_{2}^{0}$. Q.E.D.

Thus, the belief that firms are more inaccurate (so that $\sigma_{w}$ is low) leads workers who get an $s_{1}$ equal to one to expect lower wages on the outside, while it leads workers who get an $s_{1}$ equal to zero to expect higher wages on the outside. The reason is that a low value of $\sigma_{w}$ leads workers to regard both the current realization of $s_{1}$ and the future realization of $s_{2}$ as likely to be mistaken. As $\sigma_{w}$ falls, workers deem it more likely that a 
high realization of $s_{1}$ will be followed by a low realization of $s_{2}$. Thus, an employee who gets a high $s_{1}$ becomes less optimistic about his compensation on the outside. Similarly, an employee with a low $s_{1}$ becomes less pessimistic about his compensation by an alternate type $S$ firm.

Note that $\sigma_{w}$ matters only because it affects workers' subjective distribution of the wages they would be paid by their next employer if they quit their current job. Thus, $\sigma_{w}$ would not matter if workers had independent knowledge of the distribution of future wage offers conditional on a worker's characteristics including their current wage. Obtaining this information directly by moving frequently is costly, however. Aggregate statistics describing the wage changes of job movers will generally not suffice as these depend critically on the distribution of $n$, which affects the extent to which job changers started out with different values of $s_{1}$. More generally, workers are likely to know little about the distribution of shocks that prompt workers to move, particularly because such moves can also be due to changes in worker productivity that I have ignored in my analysis. This ignorance reduces the value of information about the wage distribution of job changers. The result is that general opinions about the fairness of firms, which I have captured through the parameter $\sigma_{w}$, can play a role in workers' quitting decisions.

\section{First-Period Wages}

I now turn to the analysis of the wages paid in period 1 by firms of type $S$. I denote by $w_{1}^{z}$ the wages paid by these firms to the employees whose signal $s_{1}$ equals $z$. Ignoring discounting, an employee who is offered this wage and stays with his original type $S$ employer can expect to receive $w_{1}^{z}+c_{2}^{z}$ over the two periods. By leaving, the employee can expect to earn $\bar{q}_{S}+n+c_{L}^{z}$ over the two periods. Thus employees whose $s_{1}$ equals $z$ stay if their realization of $n$ is lower than the cutoff value $n_{1}^{z}$ such that

$$
w_{1}^{z}+c_{2}^{z}=q_{N}+n_{1}^{z}+c_{L}^{z}
$$

Thus employees stay with probability $F\left(w_{1}^{z}+c_{2}^{z}-q_{N}-c_{L}^{z}\right)$, and the profits of a firm that offers a wage equal to $w_{1}^{z}$ to an employee whose signal is $z$ equal

$$
F\left(w_{1}^{z}+c_{2}^{z}-q_{N}-c_{L}^{z}\right)\left[q_{S}+v r^{z}-w_{1}^{z}+F\left(w_{2}^{z}-q_{N}\right)\left(q_{S}+v r^{z}-w_{2}^{z}\right)\right] .
$$

In this expression, the term in square brackets takes into account that the presence of the employee in the first period leads to a probability $F\left(w_{2}^{z}-q_{N}\right)$ that the employee also stays in the second period. The firm 
thus maximizes (20) with respect to $w_{1}^{z}$ while taking $w_{2}^{z}$ as given. Assuming an interior solution, the first-order condition that characterizes $w_{1}^{z}$ is

$$
\begin{gathered}
f\left(w_{1}^{z}+c_{2}^{z}-q_{N}-c_{L}^{z}\right)\left[q_{S}+v r^{z}-w_{1}^{z}+F\left(w_{2}^{z}-q_{N}\right)\left(q_{S}+v r^{z}-w_{2}^{z}\right)\right] \\
-F\left(w_{1}^{z}+c_{2}^{z}-q_{N}-c_{L}^{z}\right)=0 .
\end{gathered}
$$

Differentiating (21) with respect to the wage and to $c_{L}^{z}$, and using (21) gives

$$
\frac{d w_{1}^{z}}{d c_{L}^{z}}=\frac{f^{2}-f^{\prime} F}{2 f^{2}-f^{\prime} F},
$$

where $F, f$, and $f^{\prime}$ are evaluated at $\left(w_{1}^{z}+c_{2}^{z}-\bar{q}_{S}-c_{L}^{z}\right)$. The second-order condition ensures that the denominator is positive. My assumption that $f / F$ is uniformly decreasing in $n$ implies that the numerator is positive as well. An increase in expected outside compensation in the second period then leads firms of type $S$ to raise their first-period wage. This, together with proposition 3, implies immediately the following proposition.

Proposition 4. An increase in $\sigma_{w}$ increases $w_{1}^{1}$ and reduces $w_{1}^{0}$.

Thus, an increase in $\sigma_{w}$ increases the dispersion of the initial wages offered by firms of type $S$ if $w_{1}^{1}$ exceeds $w_{1}^{0}$. While the necessary conditions for this to occur are much weaker, a sufficient condition is given by the following proposition.

Proposition 5. If $f^{\prime} \geq 0, w_{1}^{1}>w_{1}^{0}$.

Proof. Let $w_{1}^{0}$ be the optimal wage when $s_{1}=0$. The optimal wage $w_{1}^{1}$ exceeds this wage if the left-hand side of (21) is positive for $z$ equal one when $w_{1}^{1}$ is set equal to $w_{1}^{0}$. I demonstrate that this is the case by holding constant $w_{1}$ and $c_{L}$ and showing that increases in $v r^{z}$ that are accompanied by the corresponding increases in $w_{2}^{z}$ and $c_{2}^{z}$ raise the lefthand side of (21). The monotonicity of $f / F$ together with $c_{L}^{1}>c_{L}^{0}$ then ensure that the left-hand side of (21) evaluated at the point where $w_{1}^{1}$ is equal to $w_{1}^{0}$ is indeed positive.

Let $d$ denote the derivative of $c_{2}^{z}$ with respect to changes in $v r^{z}$. This is given by the expression in (10) times $F\left(w_{2}^{z}-q_{N}\right)$, so that it is positive and less than one. Using the envelope theorem for the optimality of $w_{2}^{z}$, the change in the left-hand side of (21) as one changes $v r^{z}$ while varying $w_{2}^{z}$ and $c_{2}^{z}$ is

$$
\begin{aligned}
d f^{\prime}\left[q_{s}\right. & \left.+v r^{z}-w_{1}^{0}+F\left(w_{2}-q_{N}\right)\left(q_{s}+v r^{z}-w_{2}^{z}\right)\right] \\
& +f\left[1+F\left(w_{2}^{z}-q_{N}\right)-d\right],
\end{aligned}
$$

where $f$ and $f^{\prime}$ are evaluated at $\left(w_{1}^{0}+c_{2}-q_{N}-c_{L}^{0}\right)$. Since $d<1$ this expression is positive if $f^{\prime}$ is nonnegative, though this condition is clearly stronger than necessary. Q.E.D.

The uniform distribution simultaneously satisfies the condition that 


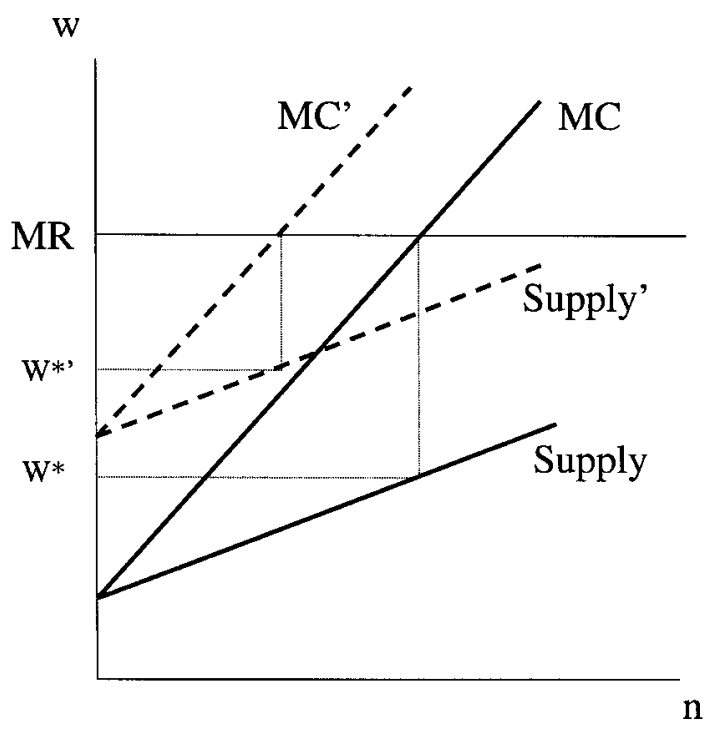

FIG. 2.-Wage determination

$f / F$ be monotonically decreasing in $n$ and the condition that $f^{\prime}$ be nonnegative. Thus, the gap between $w_{1}^{1}$ and $w_{1}^{0}$ is increasing with $\sigma_{w}$ for this distribution. This gap corresponds, broadly, to the variability of wages inside firms. Consider next the gap between the highest and lowest firstperiod wage paid in the model economy, which corresponds broadly to measures such as the interdecile range. Whether $q_{N}$ represents the lowest, the middle, or the top wage, this measure of inequality rises with $\sigma_{w}$ as long as $w_{1}^{0}$ falls and $w_{1}^{1}$ rises.

The model also has implications for turnover, and I turn to these next. Differentiating (19)

$$
\frac{d n_{1}^{z}}{d \sigma_{w}}=-\frac{d c_{L}^{z}}{d \sigma_{w}}\left(1-\frac{d w_{1}^{z}}{d c_{L}^{z}}\right)=\frac{-f^{2}}{2 f^{2}-f^{\prime} F} \frac{d c_{L}^{z}}{d \sigma_{w}},
$$

where the second equality follows from (22). This means that, in spite of the corresponding increase in $w_{1}^{z}$, a rise in $c_{L}^{z}$ unambiguously lowers the cutoff $n_{1}^{z}$ at which employees leave and thereby raises the number of quits. Therefore, a reduction in $\sigma_{w}$ increases the turnover of employees whose $s_{1}$ is equal to zero, while it lowers the turnover of employees whose $s_{1}$ is equal to one.

I now provide some intuition for the result that increases in $\sigma_{w}$ raise the relative turnover of high $s_{1}$ individuals together with their relative wages. Figure 2 helps one interpret these results. This figure shows the labor supply curve given, implicitly, by (19). This is a labor supply curve 
because a higher wage leads workers to have a higher cutoff $n_{1}^{z}$, so that the fraction of this type of workers staying at the firm, $F\left(n_{1}^{z}\right)$, rises. The firm then has a conventional monopsony problem in which there is a marginal cost of labor that lies above the labor supply curve and a marginal revenue from an additional unit of labor which, in this case, is horizontal. The equilibrium cutoff is the one that ensures that marginal cost is equal to marginal revenue, and the equilibrium wage ensures that this cutoff is on the labor supply curve.

An increase in $c_{L}$ for this worker (which would result if the employee had an $s_{1}$ equal to zero and $\sigma_{w}$ fell) shifts the labor supply curve to the left because it raises what the worker can expect to earn outside and thereby makes departures more attractive. This leads to a reduction in the cutoff, so that more workers of this type leave in equilibrium and, at least when labor supply is linear, the equilibrium wage increases. An increase in $\sigma_{w}$ lowers $c_{L}$ for workers with $s_{1}$ equal to zero while raising it for those with $s_{1}$ equal to one, so that it moves the labor supply curve of employees with $s_{1}$ equal zero to the right, while it moves that of employees with $s_{1}$ equal to one to the left. It thus increases the relative turnover and wages of high $s_{1}$ workers.

Before closing this section, it is worth computing wages and turnover in the case where $F$ is uniform for $n$ between 0 and $1 / h$. This means that, when the optimal second-period wage is interior, (2) reduces to

$$
w_{2}^{z}=\frac{q_{S}+q_{N}+v r^{z}}{2}
$$

and this applies as long as the second inequality in (3) is satisfied, or

$$
q_{S}+q_{N}+v r^{2}<2 / h
$$

Equation (11) then implies that the expected second-period compensation is

$$
c_{2}^{z}=b\left(w_{2}^{z}-q_{N}\right) w_{2}^{z}+\int_{w_{2}^{z}-q_{N}}^{1 / b}\left(q_{N}+n\right) b d n .
$$

Carrying out the integration, this is

$$
c_{2}^{z}=q_{N}+\frac{b}{2}\left(w_{2}^{z}-q_{N}\right)^{2}+\frac{1}{2 b} .
$$

This falls with $b$ when $w_{2}^{z}$ is equal to $q_{N}$ because an increase in $b$ lowers the mean of the value of outside offers. 
Substituting the wage in (24) into (26), (21) becomes

$$
b\left[q_{S}+v r^{z}+b\left(\frac{\delta^{z}}{2}\right)^{2}-w_{1}^{z}\right]-b\left[w_{1}^{z}+\frac{b}{2}\left(\frac{\delta^{z}}{2}\right)^{2}+\frac{1}{2 b}-c_{L}^{z}\right]=0,
$$

where $\delta^{z}=q_{S}-q_{N}+v r^{z}$ is the difference between the expected output of an employee with $s_{2}=z$ at a type $S$ and a type $N$ firm.

The optimal first-period wage is thus

$$
2 w_{1}^{z}=q_{s}+v r^{z}-\frac{1}{2 b}+c_{L}^{z}+\frac{b}{2}\left(\frac{\delta^{z}}{2}\right)^{2},
$$

which is clearly larger for $z$ equal to one.

\section{Aggregate "Output"}

In this section I show that increases in $\sigma_{w}$ can reduce the sum of the output produced by firms and the nonpecuniary utility enjoyed by individuals. I denote the per capita value of this aggregate output in period $t$ by $\Omega_{t}$. Even when changes in $\sigma_{w}$ raise $\Omega_{t}$, this by no means implies that such changes lead to Pareto improvements. Indeed, they generally do not, since some workers see their wages rise while others see their wages decline. Still, it is useful to know the reasons why increasing trust in capitalism by increasing $\sigma_{w}$ can lower, in some sense, the total value of the pie that is produced.

Given that a fraction $\phi$ of individuals receive a signal $s_{1}$ equal to one, per capita output in period 1 is equal to

$$
\begin{aligned}
\Omega_{1}= & (1-\phi)\left[F\left(n_{1}^{0}\right)\left(q_{S}+v r^{0}\right)+\int_{n_{1}^{0}}^{\bar{n}}\left(q_{N}+n\right) d F(n)\right] \\
& +\phi\left[F\left(n_{1}^{1}\right)\left(q_{S}+v r^{1}\right)+\int_{n_{1}^{1}}^{\bar{n}}\left(q_{N}+n\right) d F(n)\right] .
\end{aligned}
$$

Thus, the change in $\Omega_{1}$ is equal to

$$
d \Omega_{1}=(1-\phi)\left(\delta^{0}-n_{1}^{0}\right) f\left(n_{1}^{0}\right) d n_{1}^{0}+\phi\left(\delta^{1}-n_{1}^{1}\right) f\left(n_{1}^{1}\right) d n_{1}^{1} .
$$

This change depends only on the two cutoffs $n_{1}^{0}$ and $n_{1}^{1}$. An increase in either cutoff leads to a gain in output that is proportional to the difference between the marginal employee's total output (inclusive of nonpecuniary compensation) in a type $S$ firm and in a type $N$ firm. The existence of a monopsonistic distortion in firms of type $S$ together with its absence in firms of type $N$ implies that this difference is positive, because workers get paid less than their marginal product in the former. As a result, we have the following proposition. 
Proposition 6. If $F$ is uniform between 0 and $1 / h, d \Omega_{1} / d \sigma_{w}<0$ as long as

$$
0<\frac{\delta^{1}}{2}+\frac{b}{8}\left(\delta^{1}\right)^{2}+\frac{b(1-\phi)}{16}\left[1-\left(\frac{\sigma-\phi}{1-\phi}\right)^{2}\right]\left[\left(\delta^{1}\right)^{2}-\left(\delta^{0}\right)^{2}\right]<\frac{1}{b} .
$$

If $(30)$ is violated while

$$
0<\frac{\delta^{0}}{2}+\frac{b}{8}\left(\delta^{0}\right)^{2}+\frac{b \phi}{16}\left[1-\left(\frac{\sigma-\phi}{1-\phi}\right)^{2}\right]\left\{\left(\delta^{0}\right)^{2}-\min \left[\frac{2}{b^{2}},\left(\delta^{1}\right)^{2}\right]\right\}<\frac{1}{b},
$$

$d \Omega_{1} / d \sigma_{w}>0$. If the second inequality in (31) is violated as well, no employee departs firms of type $S$ in the first period, so that $\sigma_{w}$ has no effect on output. For the proof of proposition 6, see the appendix.

Condition (30) effectively ensures that some workers with $s_{1}=1$ quit (so $n_{1}^{1}<\bar{n}$ ), and this occurs only for certain values of $\left(q_{S}-q_{N}\right)$ and $v$. Then, employees with both realizations of $s_{1}$ alter their quitting behavior as $\sigma_{w}$ changes. Output in period 1 then falls with $\sigma_{w}$ because, in the uniform case, the difference between the marginal employee's output at a firm of type $S$ and at a firm of type $N$ is larger for workers whose $s_{1}$ equals one. The reason is related to the result in proposition 2: the difference between an employee's wage and his marginal product is larger for more productive employees, so that society has more to lose from having these employees depart from their type $S$ employer. This then implies that increases in $\sigma_{w}$ lower aggregate output, because the cost that results from the reduction in the attachment of more productive workers is larger than the gain that results from the increased attachment of less productive workers.

For other parameter values, particularly those where $q_{S}-q_{N}, v$, or $b$ are relatively large, (30) can be violated while (31) holds. High values of these parameters imply that firms of type $S$ raise wages to raise the probability of keeping their employees. They might then keep all employees whose $s_{1}$ equals one, while setting wages so that some employees with $s_{1}=0$ depart. Then, only the turnover of employees with $s_{1}=0$ is reduced when $\sigma_{w}$ increases. This raises output because, at the margin, these employees produce more inside type $S$ firms.

I now turn my attention to second-period per capita output, which I denote by $\Omega_{2}$.

Proposition 7. In response to changes in $n_{1}^{0}$ and $n_{1}^{1}$, the change in $\Omega_{2}$ is given by

$$
\begin{gathered}
\mathrm{d} \Omega_{2}=\mathrm{P}\left(\mathrm{s}_{2}=0 \mid \mathrm{s}_{1}=1\right)\left\{\int_{\mathrm{w}_{2}^{0}-q_{\mathrm{N}}}^{\mathrm{w}_{2}^{2}-\mathrm{q}_{\mathrm{N}}}\left[\mathrm{vP}\left(\mathrm{r}=1 \mid \mathrm{s}_{1}=1, \mathrm{~s}_{2}=0\right)-\mathrm{q}_{\mathrm{N}}-\mathrm{n}\right] \mathrm{dF}(\mathrm{n})\right\} \mathrm{f}\left(\mathrm{n}_{1}^{1}\right) \mathrm{d} \mathrm{n}_{1}^{1} \\
-\mathrm{P}\left(\mathrm{s}_{2}=1 \mid \mathrm{s}_{1}=0\right)\left\{\int_{\mathrm{w}_{2}^{0}-\mathrm{qN}_{\mathrm{N}}}^{\mathrm{w}_{2}^{1}-\mathrm{q}_{\mathrm{N}}}\left[\mathrm{vP}\left(\mathrm{r}=1 \mid \mathrm{s}_{1}=0, \mathrm{~s}_{2}=1\right)-\mathrm{q}_{\mathrm{N}}-\mathrm{n}\right] \mathrm{dF}(\mathrm{n})\right\} \mathrm{f}\left(\mathrm{n}_{1}^{0}\right) \mathrm{dn}_{1}^{0} .
\end{gathered}
$$


Proof. Start with the last term. A small reduction in $n_{1}^{\circ}$ increases by $-f\left(n_{1}^{0}\right) d n_{1}^{0}$ the number of employees with $s_{1}=0$ that leave their original type $S$ employers. If these employees draw an $s_{2}$ equal to zero, their output in the second period is the same as if they had stayed with their original type $S$ employer regardless of the value of their $n$. If they get an $s_{2}$ equal to one and their realization of $n$ is either below $w_{2}^{0}-q_{N}$ or above $w_{2}^{1}-$ $q_{N}$, their total output is again the same because, whether they originally stay or leave, they work at a type $S$ firm in period 2 in the former case and at a type $N$ firm in the latter. Their period-2 behavior is different only if, after they leave, they get an $s_{2}$ equal one while their realization of $n$ lies between $w_{2}^{0}-q_{N}$ and $w_{2}^{1}-q_{N}$. This leads them to stay at the type $S$ firm in period 2, whereas they would have left their original type $S$ firm if they had stayed in the first period. As a result, such employees see their output increase by $q_{S}-q_{N}+v E r-n$, where the expectation of $r$ must be computed taking into account that $s_{1}=0$ while $s_{2}=1$.

Similarly, a small reduction in $n_{1}^{1}$ increases by $-f\left(n_{1}^{1}\right) d n_{1}^{1}$ the number of employees with $s_{1}=1$ that leave their original type $S$ employers. If these individuals draw an $s_{2}$ equal to one, their output is again unchanged regardless of the realization of $n$. Their behavior changes only if they draw an $s_{2}$ equal to zero and an $n$ between $w_{2}^{0}-q_{N}$ and $w_{2}^{1}-q_{N}$. This now leads them to leave their new type $S$ firm in period 2, whereas they would have stayed with their original type $S$ firm if they had stayed in the first period. Their output thus falls by $q_{S}-q_{N}+v E r-n$, where the expectation of $r$ must be computed taking into account that $s_{1}=1$ while $s_{2}=$ O. Q.E.D.

Note that the two terms in curly brackets in (32) are equal. If these integrals are positive, $\Omega_{2}$ falls when $\sigma_{w}$ rises. This, in turn, occurs if individuals whose signals are mixed (in the sense that they get one signal equal to one and one signal equal to zero) and whose nonpecuniary compensation in type $N$ firms have values between $\left(w_{1}^{0}-q_{N}\right)$ and $\left(w_{1}^{1}-q_{N}\right)$ are more productive on average when they work in type $S$ firms. That this condition leads to an output loss can be seen by focusing first on individuals with $s_{1}=1$ and $s_{2}=0$. By leaving their original type $S$ employer, these individuals now work for type $N$ employers in the second period when $n$ falls in this range, and this condition implies that their resulting output is on average lower. This condition implies also that individuals who stay after receiving an $s_{1}$ equal to zero lower their social output in period 2 in those states of nature where they would have gotten an $s_{2}$ equal to one had they left their original type $S$ employer. 
Once again, one can obtain more definite results in the uniform case. Then,

$$
\begin{aligned}
& \int_{w_{2}^{0}-q_{N}}^{w_{2}^{1}-q_{N}}\left[v P\left(r=1 \mid s_{1}=1, s_{2}=0\right)-q_{N}-n\right] d F(n)= \\
& \quad b\left(w_{2}^{1}-w_{2}^{0}\right)\left[q_{S}+v P\left(r=1 \mid s_{1}=1, s_{2}=0\right)-\frac{w_{2}^{1}-w_{2}^{0}}{2}\right],
\end{aligned}
$$

so that $\Omega_{2}$ falls if $q_{s}+v P\left(r=1 \mid s_{1}=1, s_{2}=0\right)-\left(w_{2}^{1}-w_{2}^{0}\right) / 2$, which I denote by $\Delta$, is positive. This requires that expected output in a firm of type $S$ of an employee with a mixed signal is higher than the arithmetic average between the wages paid to high and low signal employees in the second period. Moreover, I provide the following proposition.

Proposition 8. If $F$ is uniform, sufficient conditions for $\Delta>0$ include:

i) $q_{s}-q_{N}+v[(1-\sigma) \phi] /(1+\sigma-2 \phi)>0$;

ii) $\phi<3 / 4$; and

iii) $\phi \geq 3 / 4$ and $\sigma-\phi>4(1-\phi)(\phi-.75) /(4 \phi-1)$, where this latter number is no greater than .026 .

There do, however, exist parameters that violate all these conditions and that ensure that $\Delta<0$, so that $d \Omega_{2} / d \sigma_{w}>0$. See the appendix for the proof of proposition 8 .

It follows immediately that $\Omega_{2}$ falls with $\sigma_{w}$ if $q_{s}>q_{N}$, which is equivalent to assuming that there exist realizations of $n$ low enough that it is more efficient for the employee to stay at a firm of type $S$ even if he is sure that his $r$ is equal to zero. Indeed, what is needed to overturn the conclusion that $d \Omega_{2} / d \sigma_{w}<0$ is that the productivity of employees in firms of type $N, Q_{N}$ be relatively high. At the same time, condition (5), which requires that employees sometimes be more productive in firms of type $S$ even if their $s_{1}$ is equal to zero, puts a limit on $q_{N}$, since it requires that

$$
q_{N}<q_{S}+\frac{\phi(1-\sigma)}{1-\phi} \text {. }
$$

The violations of ii and iii in proposition 8 arise only when $\phi$ is high and $\sigma$, while greater than $\phi$, is relatively low. Such combinations of parameters allow $q_{N}$ to be relatively high without violating (5). It then becomes possible that $d \Omega_{2} / d \sigma_{w}>0$, because more is produced when employees with mixed signals switch to type $N$ firms when they draw offers whose value is between $w_{2}^{0}$ and $w_{2}^{1}$.

That there is a broad range of parameters for which $d \Omega_{2} / d \sigma_{w}>0$ is not unexpected. Since firms pay workers less than their marginal products, it is not too surprising that the average of $w_{1}^{0}$ and $w_{1}^{1}$ can be below the 
expected marginal product of a worker with mixed signals. Increases in $\sigma_{w}$ then lower $\Omega_{2}$ in the uniform case. This conclusion can be overturned if productivity in sector $N$ is sufficiently high, because the monopsony distortion is lower in this case. Faced with employees whose productivity in sector $N$ is high, firms of type $S$ raise wages and thereby reduce the extent to which productivity in sector $S$ exceeds wages. Still, because productivity is always at least somewhat greater than wages, the range of parameters such that $d \Omega_{2} / d \sigma_{w}>0$ is relatively small.

To summarize the results of this section, increases in $\sigma_{w}$ have the potential to lower output in both periods, both because they reduce the most productive attachments in period 1 and because they reduce the extent to which individuals who either get or would have gotten mixed signals work in type $S$ firms in the second period. If (30) and any of the three conditions in proposition 8 hold, aggregate output actually falls in both periods. This is the case for a broad range of parameters including, for example, setting $q_{s}, q_{N}, v$, and $b$ equal one, while $\phi=.7$ and $\sigma=$ .9. When $v$ is increased beyond about 1.6, (30) ceases to hold, and $\Omega_{1}$ rises with $\sigma_{w}$. Another method for violating (30) is to raise $h$. By raising $h$ to 4 , keeping $q_{s}$ and $q_{N}$ equal to 1 , and setting $\sigma, \phi$, and $v$ to $.9, .89$, and .462 , respectively, the gains in $\Omega_{1}$ from raising $\sigma_{w}$ exceed the losses in $\Omega_{2}$.

It is also straightforward to find numerical values such that all the conditions of proposition 8 are violated and $\Omega_{2}$ rises with $\sigma_{w}$. However, because this occurs only when $\delta^{0}$ is close to zero, $h$ must be small to ensure that the first inequality of (31) holds. In my numerical experiments, these low values of $h$ made it impossible to violate (30). I was unable to find parameters for which output rises in both periods.

\section{Empirical Relevance}

The model predicts that populations that differ only in their beliefs about the extent to which pay reflects productivity will have different distributions of both turnover and wages. Unfortunately, data on the extent to which people feel that compensation is tied to productivity do not appear to exist, and this limits the extent to which one can ascertain the importance of these beliefs for labor market outcomes. While these beliefs are not observable, other variables that would seem to be closely related to these beliefs can be measured. In particular, individuals in different countries differ both at a point in time and over time in the programs of their elected representatives and in the typical responses they give to surveys asking about the desirability of income redistribution. In the absence of improved data, I treat countries where redistribution is favored (and whose elected representatives reflect this) as being more skeptical about the extent to which differences in compensation reflect differences 
in productivity. There may well be other reasons why people see inequality as excessive. They may, for example, regard inequality as a problem because they see poor individuals as unable to meet what are regarded as basic needs. However, Hochschild (1981, pp. 111, 140) reports that both her rich and her poor (U.S.) respondents favored tying income to individual productivity and differed mainly in the extent to which they regarded this as occurring in practice.

I first study the connection between beliefs and inequality, and then I turn to the connection between inequality (or beliefs) and turnover. The data on beliefs are more extensive at a point in time for different countries, and so I start with this. I then discuss the little bit of data that is available about changing beliefs through time.

Figure 3 focuses on seven countries at a point in time. It shows the relationship between the attitudes toward inequality from the 1987 International Social Survey as well as inequality measures from around the same period. ${ }^{10}$

The vertical axis of this figure gives the fraction of people who agree with the statement that "Differences in income in [respondent's country] are too large." These figures are drawn from Evans (1993). ${ }^{11}$ On the horizontal axis, the figure gives the Gini coefficient for household pretax income. These figures are drawn from Deininger and Squire (1996), who report inequality measures from a number of sources. To help make these figures comparable, I used figures from the Luxembourg Income Study (LIS) data base (Atkinson, Rainwater, and Smeeding 1995) for all the countries for which these figures were available, namely, for all countries except Austria and Australia. ${ }^{12}$ The correlation between these figures is -.72 . Such a negative correlation fits with the model presented earlier if one regards the opinion that inequality is too large as closely related to the opinion that individual pay does not reflect individual performance.

There are, of course, alternative interpretations. One possibility is that the perception of large inequities leads to government policies that reduce actual inequality. In an extreme version of this interpretation, perceptions affect incomes only through their effect on policies. One way these pol-

\footnotetext{
${ }^{10}$ Inequality measures change slowly over time, so that it should not matter very much that these measurements were not all taken precisely in 1987.

${ }^{11}$ The only other country included in this international survey was Hungary, which I excluded because I felt that the data on actual inequality were probably not very meaningful during its postcommunist transformation.

${ }^{12}$ I picked, for each country, the observation that was closest to 1987. The data for Switzerland are from 1982, those for Germany are from 1983, those for Norway, the United Kingdom, and the United States are from 1986, and those for Ireland and the Netherlands are from 1987. The Australian data come from the 1989 Statistical Yearbook for Australia, while those for Austria, whose data are probably the least comparable to the others, comes from 1987.
} 


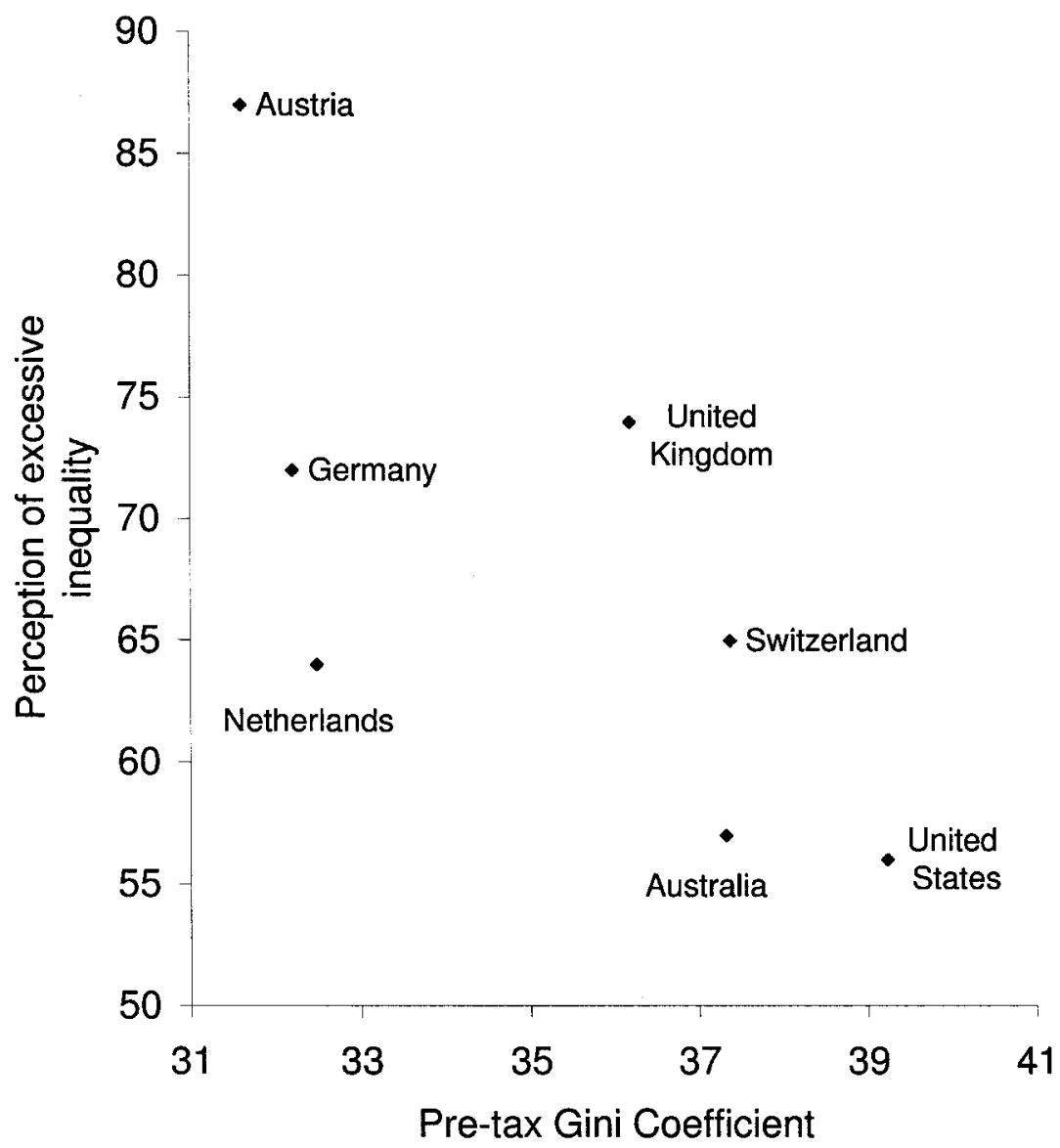

FIG. 3.-Actual and perceived inequality

icies could be leading to the negative correlation in figure 3 is by affecting the measured income distribution itself. The measure of pretax household income on which my Gini coefficients are based includes some government transfers and cash transfers to poor people, which might be larger in countries where people dislike inequality more. I have thus also looked at Organization for Economic Cooperation and Development (OECD) measures of the distribution of labor earnings. The coverage of these data is not uniform for the seven countries in my sample. For Austria, the United Kingdom, and the United States, the figures appear to be comparable, and the ratio D9/D5 is largest in the United States, intermediate in the United Kingdom, and smallest in Austria. The D5/D1 ratio is highest in the United States and lower for the United Kingdom and 
Austria, though the latter two numbers are essentially identical. These figures are broadly consistent with the Gini coefficients for pretax income.

Another source of potential endogeneity is that high-income people might work less in countries where perceived inequality is higher because tax rates are more progressive. ${ }^{13}$ In practice, it is not clear that the countries in my sample in which inequality is seen as particularly excessive have particularly progressive income taxes. The correlation of the Gini coefficients based on after tax household income (all of which come from the LIS data base) with the Evans measure is only -.40.

It may also be possible to rationalize the findings in figure 3 by using the gift exchange model of Akerlof (1982). In that model, worker effort depends on the relationship between a worker's wage and his "reference wage," which Akerlof supposes to be the wage earned by similar workers. If the extent to which people see inequality as excessive is related to workers' reference wages, this dislike could affect equilibrium wages. In particular, one might imagine that societies where inequality is regarded as more excessive are ones where low-paid workers have higher reference wages (because they see themselves as more similar to higher-paid workers), while workers who are paid more have lower reference wages. This is not enough to ensure that wage dispersion is lower in such societies. Dispersion falls if firms have more to gain from raising wages of lowwage workers (and less to gain from raising wages to high-wage workers) in such societies. This might occur if, for example, workers whose wage is below their reference wage increase their effort by more in response to an increased gift of the firm than do workers whose wage is already above the reference wage. It might also occur if increasing the wages of high-paid workers discourages effort of low-paid workers in the same firm. While this idea still requires development, it suggests that an effortbased efficiency wage model in which norms of gift giving play a role might have similar implications to those of the turnover-based efficiency wage model developed here.

Because it corresponds most closely to the belief that pay does not reflect performance, I focused attention on the survey that asked whether people thought income disparities were excessive. It is important to note, however, that the answer to this question is strongly positively correlated with the answer to questions that ask whether people favor additional redistribution from the rich to the poor. Evans (1993) reports a measure that gives the mean response to questions asking people whether they would like the unemployed to receive a guaranteed standard of living, whether they support more spending on benefits for the poor, whether they support a guarantee of jobs for everyone, and whether they are in

${ }^{13}$ Higher tax rates alone might account for the phenomenon if these have a bigger effect on the effort of individuals whose income is high. 
favor of a basic income for everyone. With a higher mean score representing less enthusiasm for redistribution, the correlation between this mean score and the answer plotted in figure 3 is -.80 . Similarly, the mean score against redistribution has a correlation of .78 with the pretax Gini coefficient and of .52 with the after-tax coefficient.

Time-series evidence on attitudes toward income inequality seems even harder to obtain. This is particularly surprising given that many political analysts have noted a "shift to the right" in U.S., British, and Canadian electoral outcomes. In all three countries, the late 1970s and early 1980s saw the election of political leaders like Ronald Reagan, Margaret Thatcher, and Brian Mulroney, whose rhetoric was substantially more "pro-market" than that of their predecessors. The only U.S. data I am aware of that confirms that this was accompanied by a change in people's attitude toward redistribution are reported in Kluegel and Smith (1986). These researchers conducted a national survey in 1980 and found that only $18 \%$ of their respondents disagreed with the statement that the United States was spending too much on welfare. As they say, this is substantially smaller than the $39 \%$ of the people who agreed, in a 1969 survey conducted by Feagin (1975), that the United States was spending too little on welfare. This comparison suffers from several difficulties, not the least of which is that the public perception of government policies might have been different in the two instances.

In spite of the paucity of attitudinal data, it may be reasonable to suppose that the change in electoral outcomes in these three countries is suggestive of an increased confidence in the free market system as well as a more benign view of employers. ${ }^{14}$ It would then be possible to explain the increased income inequality in these three countries over the last 20 years by this change in attitudes. What makes this explanation attractive is that, as Moss (1995) shows, inequality has worsened disproportionately in these three countries (together with Australia). By contrast, countries in continental Europe such as France, Italy, and Germany have seen their earnings inequality fall. At the same time, political leaders in these coun-

${ }^{14}$ Other changes in measured attitudes are consistent with this. As Uchitelle (1994) reports, citing a study by Richard Freeman and Joel Rogers, workers no longer view big business as an adversary. They do not blame their employers for the anxiety that they feel about their income and job security. Instead, workers regard their employers as victims of global competition that forces employers to cut costs and lay off workers. Thus, interestingly, international competition may have increased income inequality via two mechanisms. The first and the more traditional one is that this competition may have reduced the demand for lowskilled workers. The second is that the existence of this international competition may have convinced workers that their employers are not being unfair when they cut wages. This, in turn, may have exacerbated inequality through a mechanism akin to the one presented in this article. 
tries appear not to have shifted nearly as much toward a free market rhetoric.

A more distinctive source of evidence on the importance of the links highlighted in this article is the evolution of turnover. Admittedly, the model has only two periods so that, taken literally, its implications concern only whether individuals stay in jobs for one period or not. However, it seems reasonable to imagine that suitable extensions imply that job durations are shorter whenever the model implies that people are more likely to separate after one period. Suppose, in particular, that $\sigma_{w}$ rises. The model implies that more workers with $s_{1}$ equal to one quit, and this presumably corresponds in practice to relatively rapid turnover (and thus short jobs) for individuals whose wages are relatively high. I thus take the model to imply that increases in $\sigma_{w}$ ought to increase the job tenure of low-wage workers while reducing that of high-wage workers. If other forces are changing everyone's tenure equally, it should still be the case that the tenure of low-wage workers ought to rise relative to that of their higher-paid counterparts.

In practice, tenure is reduced not only by quits (as in my model) but also by employment terminations that are initiated by employers-most of which take the form of layoffs. McLaughlin (1991) shows that layoffs are significantly more likely for low-education than for high-education workers. This suggests that my model ought to be more consistent with the evolution of employment durations among individuals with relatively high levels of education.

Naturally, even if actual tenure has changed in the way predicted by my model, this could be due to other changes in the labor market, including changes in the composition of the labor force, in the average educational level, in unionization, in managerial practices, or in labor market regulations. The effects of these changes on the duration of attachments between workers and firms is unknown, and I am thus unable to control for them in my analysis. What is known is that average tenure appears to have fallen in the United States, particularly among individuals with low levels of educational attainment. The overall size of this reduction has been small, however (see Farber 1995; Diebold, Neumark, and Polsky 1996; and Swinnerton and Wial 1996). In Great Britain, Burgess and Rees (1998) show that the recent period of vast changes in labor markets has led to no secular changes in expected tenure once one controls for the demographic, educational, and occupational characteristics of workers.

To study whether the implications for tenure predicted by my model are borne out, I consider data from both the United States and France. Table 1 reports statistics obtained from the May 1979, January 1991, and February 1996 U.S. Current Population Survey. In particular, it tabulates means for the answer to the question of how many years the respondent 
Table 1

Levels of Tenure in the United States

\begin{tabular}{|c|c|c|c|c|c|c|c|c|c|c|c|c|}
\hline & \multicolumn{6}{|c|}{ Males } & \multicolumn{6}{|c|}{ Females } \\
\hline & \multicolumn{3}{|c|}{ Low income } & \multicolumn{3}{|c|}{ High income } & \multicolumn{3}{|c|}{ Low income } & \multicolumn{3}{|c|}{ High income } \\
\hline & 1979 & 1991 & 1996 & 1979 & 1991 & 1996 & 1979 & 1991 & 1996 & 1979 & 1991 & 1996 \\
\hline \multicolumn{13}{|c|}{ High school not completed: } \\
\hline Age 25-34 & 3.53 & 2.24 & 3.08 & 4.87 & 4.13 & 4.68 & 2.02 & 2.92 & 1.58 & 3.59 & 4.07 & 3.61 \\
\hline Age 35-44 & 6.28 & 6.06 & 4.54 & 8.81 & 9.52 & 8.90 & 3.78 & 2.76 & 2.50 & 6.24 & 5.79 & 5.86 \\
\hline Age 45-54 & 10.21 & 9.06 & 8.79 & 15.03 & 15.47 & 15.01 & 6.14 & 6.58 & 6.56 & 9.73 & 13.06 & 11.07 \\
\hline Age 55-64 & 11.75 & 9.29 & 8.10 & 18.11 & 17.38 & 19.51 & 7.96 & 8.15 & 10.57 & 13.25 & 14.83 & 14.53 \\
\hline \multicolumn{13}{|c|}{ High school completed: } \\
\hline Age 25-34 & 3.82 & 3.56 & 3.79 & 5.43 & 5.88 & 5.72 & 2.53 & 3.08 & 2.85 & 4.85 & 4.94 & 5.71 \\
\hline Age $35-44$ & 8.48 & 6.70 & 6.88 & 10.23 & 10.95 & 10.55 & 4.10 & 4.40 & 4.66 & 7.26 & 8.18 & 8.30 \\
\hline Age $45-54$ & 13.31 & 10.63 & 10.27 & 17.76 & 16.09 & 16.93 & 5.90 & 6.85 & 7.10 & 11.40 & 10.57 & 12.99 \\
\hline Age $55-64$ & 14.25 & 9.83 & 10.11 & 20.99 & 18.81 & 18.21 & 8.87 & 9.23 & 8.00 & 15.50 & 13.54 & 14.76 \\
\hline \multicolumn{13}{|c|}{ Attended college: } \\
\hline Age $25-34$ & 3.47 & 3.56 & 2.98 & 5.14 & 5.49 & 4.40 & 2.65 & 3.13 & 2.78 & 4.26 & 4.76 & 4.34 \\
\hline Age $35-44$ & 6.87 & 7.54 & 6.70 & 10.12 & 9.24 & 9.93 & 3.03 & 4.31 & 5.44 & 6.60 & 8.76 & 8.08 \\
\hline Age $45-54$ & 11.76 & 10.35 & 10.42 & 16.49 & 14.91 & 14.47 & 6.63 & 5.67 & 7.14 & 10.65 & 10.64 & 11.53 \\
\hline Age 55-64 & 12.85 & 10.51 & 10.04 & 20.34 & 19.45 & 15.38 & 7.89 & 9.28 & 10.43 & 13.96 & 16.21 & 15.21 \\
\hline \multicolumn{13}{|c|}{ Post-college education: } \\
\hline Age $25-34$ & 3.17 & 3.34 & 3.80 & 4.48 & 4.77 & 3.78 & 2.37 & 3.10 & 3.39 & 4.27 & 3.72 & 3.47 \\
\hline Age $35-44$ & 7.56 & 7.26 & 6.31 & 9.48 & 9.20 & 8.60 & 5.06 & 6.50 & 6.88 & 8.01 & 8.33 & 7.83 \\
\hline Age $45-54$ & 11.82 & 12.56 & 11.00 & 15.03 & 14.02 & 14.06 & 8.75 & 8.83 & 9.67 & 12.56 & 11.74 & 14.85 \\
\hline Age 55-64 & 14.49 & 16.27 & 11.69 & 18.53 & 19.02 & 14.82 & 13.44 & 11.25 & 12.61 & 16.94 & 16.32 & 16.92 \\
\hline
\end{tabular}


has worked for his or her current employer. What makes these surveys particularly useful is that they simultaneously asked for information on earnings. For each of these surveys, I first divided the data into cells corresponding to gender, to four educational attainment categories, and to four age categories. For each of these 32 categories, I then computed the median level of hourly earnings, the average job tenure for those whose hourly earnings are below the median for the cell, and the average tenure for those whose hourly earnings are above. I label those with earnings higher than the median for their cell as high income-recognizing that this abuses the language somewhat, since those with low educational attainment tend to have incomes that are low relative to the population as a whole even if their income is above the median for their cell. ${ }^{15}$ Table 1 presents, for each gender-education-age-income category, the average tenure in the three survey dates.

Table 2 presents analogous data from France. These data come from the Enquète Emploi, which was conducted yearly from 1982 to 1998, and includes observations on tenure, monthly earnings, and hours. Francis Kramarz kindly computed median hourly earnings for 140 gender-education-age categories as well as mean tenure for those earning above and below this level of earnings. For the purpose of displaying these data, I have taken means across subcategories so that the age and education categories in table 2 are somewhat less disaggregated.

Consistent with the literature on earnings and seniority (see, e.g., Abraham and Farber 1987), workers whose wages are relatively high given their age and education tend to have spent more time with their current employer. My model implies this as well, as individuals with $s_{1}=1$ receive a higher wager that reduces their probability of quitting. ${ }^{16} \mathrm{It}$ is interesting that higher levels of education are only weakly associated with higher levels of tenure (for a given age). ${ }^{17}$

\footnotetext{
${ }^{15}$ I control for education and other observable characteristics in this way both because these variables are known to affect tenure and because the model's income differences are due to signals that only employers observe. In an appendix available on request, I also consider an extension that shows that the model can also imply that increases in $\sigma_{w}$ raise inequality across individuals who differ in observable characteristics such as educational attainment.

${ }^{16}$ An alternative view is that this correlation results from the automatic escalation of wages with seniority. See Abraham and Farber (1987) for a discussion and evidence against this alternative view.

${ }^{17}$ For example, U.S. males between the ages of 35 and 44 who have attended college for some time have generally had lower completed spells of employment with their current employer than have males of the same age who have only completed high school. Still, there is a sense in which, on average, more educated individuals have slightly longer levels of tenure. In particular, consider the ratio for a given gender-age category of the average tenure of individuals in the two high education categories to the average tenure of the individuals in the corre-
} 
Consistent with the findings of Burgess (1999), average tenure levels tend to be considerably longer in France than in the United States. This is true both for high-income individuals (which is consistent with a lower $\sigma_{w}$ in France) and for low-income individuals. This latter fact is not consistent with the model I presented above if differences in $\sigma_{w}$ are the only differences across countries. However, this fact might be consistent with an extension where firms make inferences about the quality of their employees from the fact that these have left their previous employer. If highwage individuals tend to stay with their employers, the pool of job changers is of lower quality on average, and this might promote sufficiently low wages for job changers that low-wage individuals are also more reluctant to change jobs. Whether an extension along these lines can explain these relative tenure levels is a topic for further research. I now focus on the changes in tenure over time in the two countries.

Table 3 provides some simple transformations of the data in table 1 that permit one to visualize the changes in tenure both from 1979 to 1991 and from 1991 to $1996 .{ }^{18}$ The first eight columns show, for all the genderage-education-income categories, the ratios of average tenure in 1991 to the average tenure in 1979 as well as the corresponding ratios for 1991 to 1996. With rare exceptions it is not the case that average tenure grew for low-income individuals and shrank for high-income individuals. A weaker implication of the model is that tenure for different categories of individuals ought to have grown differentially. This is analyzed in the last two columns. These give, for each category, the difference between the $\log$ growth rate of tenure for high-wage individuals from 1979 to 1996 and the corresponding log growth rate for low-wage individuals. The theory implies that this ought to be negative in the United States.

This turns out to be true when one looks at females as a whole. It is also true on average for individuals who have stayed in school beyond high school, whether they be male or female. Moreover, high-wage higheducation individuals saw their tenure fall relative to that of low-wage high-education individuals not only overall from 1979 to 1996 but also over each of the two subperiods. The opposite turns out to be the case for individuals with less education. ${ }^{19}$ As I suggested above, layoffs account for a disproportionate number of the separations of employees with low levels of education, so that my model ought to be more relevant for high-

sponding two low-education categories. The average ratio of this sort (across gender and age categories as well as across years) is 1.04 .

${ }^{18}$ According to Bernstein and Mishel (1997), inequality in the United States continued to grow in the second subperiod.

${ }^{19}$ The first two columns do show, however, that the tenure of high-income, low-education females grew less quickly than the tenure of low-income loweducation females in the period 1979-91 (with the opposite being true in the period 1991-96). 
Table 2

Evolution of Tenure in France

\begin{tabular}{|c|c|c|c|c|c|c|c|c|c|c|c|c|}
\hline & \multicolumn{8}{|c|}{ Levels of Tenure } & \multirow{2}{*}{\multicolumn{4}{|c|}{ Tenure 1998/Tenure 1982}} \\
\hline & \multicolumn{4}{|c|}{ Males } & \multicolumn{4}{|c|}{ Females } & & & & \\
\hline & \multicolumn{2}{|c|}{$\begin{array}{l}\text { Low } \\
\text { Income }\end{array}$} & \multicolumn{2}{|c|}{$\begin{array}{l}\text { High } \\
\text { Income }\end{array}$} & \multicolumn{2}{|c|}{$\begin{array}{l}\text { Low } \\
\text { Income }\end{array}$} & \multicolumn{2}{|c|}{$\begin{array}{l}\text { High } \\
\text { Income }\end{array}$} & \multicolumn{2}{|c|}{ Males } & \multicolumn{2}{|c|}{ Females } \\
\hline & 1982 & 1998 & 1982 & 1998 & 1982 & 1998 & 1982 & 1998 & Low Income & High Income & Low Income & High Income \\
\hline \multirow{2}{*}{\multicolumn{13}{|c|}{ No diploma and CEP: }} \\
\hline & 5.52 & & 6.43 & 5.84 & 5.46 & 3.60 & 6.27 & 5.73 & .76 & .91 & .66 & .91 \\
\hline $\begin{array}{l}\text { Age } 36-45 \\
\text { Age } 46-55\end{array}$ & 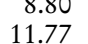 & $\begin{array}{r}9.12 \\
13.94\end{array}$ & $\begin{array}{l}11.83 \\
17.70\end{array}$ & 20.86 & 10.73 & $\begin{array}{l}6.62 \\
9.76\end{array}$ & $\begin{array}{r}9.88 \\
14.34\end{array}$ & 17.85 & $\begin{array}{l}1.04 \\
1.18\end{array}$ & $\begin{array}{l}1.14 \\
1.18\end{array}$ & .90 & 1.22 \\
\hline Age $56-65$ & 14.41 & 14.78 & 19.75 & 22.52 & 12.99 & 13.05 & 16.22 & 17.93 & 1.03 & 1.14 & 1.00 & 1.11 \\
\hline \multicolumn{13}{|c|}{ 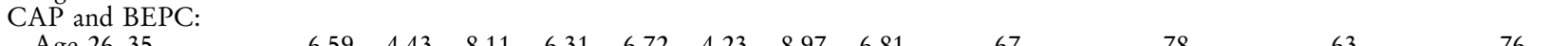 } \\
\hline Age $26-35$ & 6.59 & 4.43 & 8.11 & 6.31 & 6.72 & 4.23 & 8.97 & 6.81 & 67 & .78 & .63 & .76 \\
\hline Age 36-45 & 12.05 & 10.50 & 14.17 & 14.84 & 8.97 & 7.95 & 13.89 & 15.39 & .87 & 1.05 & .89 & 1.11 \\
\hline Age 46-55 & 15.96 & 16.63 & 21.54 & 23.29 & 12.43 & 12.39 & 20.65 & 23.45 & 1.04 & 1.08 & 1.00 & 1.14 \\
\hline Age 56- 65 & 17.15 & 21.05 & 23.13 & 26.19 & 13.10 & 14.34 & 22.68 & 23.88 & 1.23 & 1.13 & 1.09 & 1.05 \\
\hline \multicolumn{13}{|l|}{ Baccalauréat: } \\
\hline Age $26-35$ & 5.96 & 3.97 & 7.18 & 5.67 & 5.92 & 4.08 & 7.83 & 6.24 & .67 & .79 & .69 & .80 \\
\hline Age 36-45 & 11.41 & 10.25 & 13.01 & 14.17 & 10.97 & $\begin{array}{r}9.30 \\
5.16\end{array}$ & 14.10 & 15.24 & .90 & 1.09 & .85 & 1.08 \\
\hline Age $46-55$ & 16.34 & 17.32 & 20.68 & 22.44 & 12.50 & 15.16 & 21.35 & 22.80 & 1.06 & 1.09 & 1.21 & 1.07 \\
\hline Age $56-65$ & 17.64 & 22.76 & 25.64 & 27.15 & 16.79 & 16.20 & 27.12 & 26.35 & 1.29 & 1.06 & .96 & .97 \\
\hline
\end{tabular}


Post-high school:

Age 26-35
Age 36-45

Age 36-45

$\begin{array}{llllllll}4.67 & 3.26 & 5.32 & 4.12 & 4.69 & 3.33 & 6.13 & 4.78\end{array}$

Age 56-65

$\begin{array}{llllllll}10.65 & 9.78 & 11.26 & 11.11 & 10.31 & 9.38 & 12.90 & 11.86\end{array}$

Unweighted average

$\begin{array}{lllllllll}15.83 & 17.35 & 17.63 & 19.67 & 15.05 & 15.66 & 21.78 & 20.96\end{array}$

High education average

$\begin{array}{llllllll}22.91 & 18.60 & 20.95 & 28.37 & 15.52 & 17.11 & 26.60 & 26.38\end{array}$

Note. - The Certificat d'Etudes Primaires (CEP) is a certificate obtained on completion of primary school. The Certificat d'Aptitude Professionnelle (CAP)
and the Brevet d'Etudes du Premier Cycle (BEPC) involve further schooling. The latter involves academic studies, while the former also involves technical training. While the baccalauréat degree is also granted by secondary schools, it opens the door to studying at universities, and its academic requirements are 
Table 3

The Evolution of Tenure in the United States

\begin{tabular}{|c|c|c|c|c|c|c|c|c|c|c|}
\hline & \multicolumn{4}{|c|}{ Tenure 1991/Tenure 1979} & \multicolumn{4}{|c|}{ Tenure 1996/Tenure 1991} & \multirow{2}{*}{\multicolumn{2}{|c|}{$\begin{array}{l}\text { Difference between } \\
\text { Log Growth Rates } \\
\text { from } 1979 \text { to } 1996\end{array}$}} \\
\hline & \multicolumn{2}{|c|}{ Males } & \multicolumn{2}{|c|}{ Females } & \multicolumn{2}{|c|}{ Males } & \multicolumn{2}{|c|}{ Females } & & \\
\hline & $\begin{array}{l}\text { Low } \\
\text { Income }\end{array}$ & $\begin{array}{c}\text { High } \\
\text { Income }\end{array}$ & $\begin{array}{l}\text { Low } \\
\text { Income }\end{array}$ & $\begin{array}{c}\text { High } \\
\text { Income }\end{array}$ & $\begin{array}{l}\text { Low } \\
\text { Income }\end{array}$ & $\begin{array}{c}\text { High } \\
\text { Income }\end{array}$ & $\begin{array}{l}\text { Low } \\
\text { Income }\end{array}$ & $\begin{array}{c}\text { High } \\
\text { Income }\end{array}$ & Males & Females \\
\hline \multicolumn{11}{|c|}{ High school not completed: } \\
\hline Age $25-34$ & .64 & .85 & 1.45 & 1.13 & 1.37 & 1.14 & .54 & .89 & .095 & .246 \\
\hline Age 35-44 & .96 & 1.08 & .73 & .93 & .75 & .93 & .91 & 1.01 & .335 & .350 \\
\hline Age $45-54$ & .89 & 1.03 & 1.07 & 1.34 & .97 & .97 & 1.00 & .85 & .148 & .062 \\
\hline Age 55-64 & .79 & .96 & 1.02 & 1.12 & .87 & 1.12 & 1.30 & .98 & .446 & -.192 \\
\hline \multicolumn{11}{|l|}{ High school completed: } \\
\hline Age 25-34 & .93 & 1.08 & 1.22 & 1.02 & 1.06 & .97 & .92 & 1.16 & .059 & .046 \\
\hline Age $35-44$ & .79 & 1.07 & 1.07 & 1.13 & 1.03 & .96 & 1.06 & 1.01 & .239 & .006 \\
\hline Age $45-54$ & .80 & .91 & 1.16 & .93 & .97 & 1.05 & 1.04 & 1.23 & .212 & -.055 \\
\hline Age 55-64 & .69 & .90 & 1.04 & .87 & 1.03 & .97 & .87 & 1.09 & .201 & .053 \\
\hline \multicolumn{11}{|l|}{ Attended college: } \\
\hline Age $25-34$ & 1.03 & 1.07 & 1.18 & 1.12 & .84 & .80 & .89 & .91 & -.004 & -.032 \\
\hline Age $35-44$ & 1.10 & .91 & 1.42 & 1.33 & .89 & 1.07 & 1.26 & .92 & .006 & -.382 \\
\hline Age $45-54$ & .88 & .90 & .85 & 1.00 & 1.01 & .97 & 1.26 & 1.08 & -.009 & .005 \\
\hline Age 55-64 & .82 & .96 & 1.18 & 1.16 & .96 & .79 & 1.12 & .94 & -.033 & -.194 \\
\hline \multicolumn{11}{|l|}{ Post-college education: } \\
\hline Age $25-34$ & 1.05 & 1.07 & 1.31 & .87 & 1.14 & .79 & 1.09 & .93 & -.351 & -.565 \\
\hline Age $35-44$ & .96 & .97 & 1.28 & 1.04 & .87 & .94 & 1.06 & .94 & .084 & -.329 \\
\hline Age $45-54$ & 1.06 & .93 & 1.01 & .93 & .88 & 1.00 & 1.10 & 1.26 & .005 & .067 \\
\hline Age 55-64 & 1.12 & 1.03 & .84 & .96 & .72 & .78 & 1.12 & 1.04 & -.009 & .063 \\
\hline Unweighted average & .91 & .98 & 1.11 & 1.06 & .96 & .95 & 1.03 & 1.02 & .074 & -.073 \\
\hline Low education average & .81 & .98 & 1.10 & 1.06 & 1.01 & 1.01 & .95 & 1.03 & .201 & .039 \\
\hline High education average & 1.00 & .98 & 1.13 & 1.05 & .91 & .89 & 1.11 & 1.00 & -.043 & -.179 \\
\hline
\end{tabular}


Table 4

Regression Results

\begin{tabular}{lcccc}
\hline Specification & $\alpha$ & SE & $N$ & $R^{2}$ (Within) \\
\hline All observations* & .0060 & .00097 & 2,193 & .019 \\
High education $\dagger$ & .0042 & .0014 & 963 & .011 \\
High education, 1988-98 & .0130 & .0025 & 623 & .045 \\
High education, 1982-87 & .0045 & .0063 & 340 & .002 \\
Low education, males & .0042 & .0016 & 613 & .012 \\
Low education, females & .0109 & .0022 & 617 & .040 \\
\hline * Excludes two groups that included either two nonconsecutive observations or one observation. The \\
remaining groups contain at least seven observations, and all of their observations are consecutive. \\
$\quad \dagger$ Includes individuals who have either completed their baccalauréat or continued going to school after \\
high school.
\end{tabular}

education individuals. However, whether the distinction between quits and layoffs is responsible for these contrary results awaits further research.

It is interesting that French tenure for individuals with high educational attainment evolved rather differently. This can be seen in the last two columns of table 2 . These show that, on average, tenure of high-wage individuals (whether male or female) rose relative to tenure of their lowwage counterparts from 1982 to 1998 when one looks at groups with relatively high levels of education. The same is true for individuals with lower educational attainment, but this is not distinctive to France since a similar pattern is observed in the United States for males for 1982 to 1998 and for females from 1991 to 1996.

A broader view of the evolution of French tenure by income can be obtained by considering regressions that explain the evolution of a variable I call TENURERATIO ${ }_{i t}$. This variable equals the difference between the logarithm of average tenure at $t$ of individuals within group $i$ whose hourly earnings exceed median hourly earnings for the group and the logarithm of average tenure of those whose earnings are below the median. I consider, in particular, a regression of the form

$$
\text { TENURERATIO }_{i t}=c_{i}+\alpha t+\epsilon_{i t},
$$

where $c_{i}$ is a fixed effect for the group, while $\alpha$ is the coefficient on a time trend. A positive $\alpha$ thus indicates that tenure of high-wage individuals has been growing over time relative to tenure of low-wage individuals. Table 4 shows that, for various specifications, the estimated value of $\alpha$ is indeed positive. It is interesting that this coefficient is not very sensitive to the level of education of the groups that I include in the regression. In particular, it is positive and significantly different from zero also for groups with relatively high educational attainment, and this provides a contrast with the results for the United States.

The estimate of $\alpha$ tends to be higher when one drops earlier observations. The highest $t$-statistic for $\alpha$ is obtained when one uses only the observations between 1988 and 1998, and I show the resulting estimate 
in table 4. Samples that drop even more early observations tend to have even higher estimates (though the associated $t$-statistic is lower because the number of observations falls). Still, the point estimate using data only from 1982 to 1988 is positive as well.

The estimates from the subsample with somewhat less formal education are somewhat larger, particularly for women. One way to compare these results with those using U.S. data is to multiply the point estimate of $\alpha$ by 17 to compute the expected growth in the log difference in tenure between high- and low-wage individuals. In the case of women of relatively low educational attainment, this expected growth is .19, which vastly exceeds the corresponding log difference in table 3 , which is only .04. Thus, for these women, it appears that tenure has been lengthening disproportionately for high-wage workers in France, as one would predict if $\sigma_{w}$ rose more in the United States. On the other hand, the point estimates predict a growth in the log difference of tenure for males with relatively low education of only .07 , and this is much smaller than .201 , the growth in this difference in the United States over the period 1979-96.

The movements in tenure that are most consistent with those predicted by the model remain those of highly educated individuals. Among this group, U.S. high-wage workers have been reducing their tenure relative to low-wage workers, while the opposite is true in France. An alternative interpretation for this finding is that, for exogenous reasons, more opportunities have become available for high-wage high-education individuals in the United States and that these opportunities have led to "jobhopping." While this alternative cannot be dismissed, it should be kept in mind that an increase in $\sigma_{w}$ that leads high-wage workers to be willing to move may thereby encourage the endogenous creation of these opportunities.

\section{Conclusion}

This article presents an attempt at explaining widening income disparities in countries such as the United States by changes in the extent to which people believe that higher rewards flow to more productive individuals. It shows that these changes in beliefs can have a direct effect on the distribution of income even if they do not affect the inherent productivity or the effort of any worker.

For these beliefs to matter, employees must find it difficult to infer the wages they would ultimately obtain at alternate employers. This suggests that it would be worthwhile to model the extent to which individuals acquire this knowledge. Early in individuals' careers, there is a force that can lead individuals to acquire a reasonably large amount of information about wages at alternate employers. Suppose, as seems plausible, that individuals start out with inflated opinions about their abilities. If their 
first employer offers them a high wage after the initial screening period, they are likely to conclude that pay is highly correlated with productivity, while they are likely to conclude the opposite if their first job offers a low remuneration..$^{20}$ Both of these inferences lead individuals to be quite willing to try alternative employers. This, in turn, leads them to acquire hard information both about their opportunities and about the extent to which wages offered at different employers are correlated with each other (which helps them calibrate employer accuracy). It would be worthwhile to understand these dynamics better. It seems reasonable to suppose that the cost of these moves makes this process end before individuals feel they know the relevant parameters. Moreover, as tables 1 and 2 indicate, many individuals end up staying with a single employer for a long time. Employers are likely to base their wage offers to these individuals on what these individuals expect to get if they do leave, and these expectations may well rely increasingly on general information, including opinions about the accuracy of employers.

While the model assumes that beliefs are homogeneous-so as to focus on common changes in beliefs-more work deserves to be done under the assumption that communication is sufficiently difficult that beliefs remain dispersed. This dispersion is certainly consistent with the survey evidence. One might thus be able to use survey evidence to study whether individuals whose beliefs differ also act differently. Is it the case, for example, that high-wage workers who believe that pay is not strongly correlated with productivity have stayed at their current jobs for a relatively long time?

In closing, I ought to emphasize again that one advantage of the model is that it allows one to evaluate the extent to which changes in beliefs are responsible for widening income disparities in different countries by studying whether changes in tenure are consistent with these changed beliefs. I have looked at measures of average tenure for workers who fall within certain gender-age-education and income cells in both the United States and in France, and I have found some support for the model. Clearly, much more deserves to be done along these lines. It would be better, for example, to compare the separation behavior of individuals, taking into account both the history of their wages and the likely future wages at their employer. This might be done using data that identify employees and employers simultaneously as in Abowd, Kramarz, and Margolis (1999). These researchers show that employers differ in the extent to which they make their wages depend on seniority. Since workers ought to take this into account when they decide to quit, it would be useful to know

${ }^{20}$ This contrast is consistent with the observations of Hochschild (1981) mentioned earlier. 
whether quitting behavior has changed in the ways suggested by my model when this deferral of compensation is taken into account.

\section{Appendix}

In this appendix, the proofs of propositions 6 and 8 are given.

\section{Proof of Proposition 6}

I first show that (31) implies that $\delta^{0}<2 / h$, so that $w_{2}^{0}$ is given by (24). This can be seen by noting that, because $\phi<1$ and $\sigma \geq \phi$, the second inequality of (31) implies that

$$
\frac{\delta^{0}}{2}+\frac{b}{4}\left(\delta^{0}\right)^{2}<\frac{3}{2 b},
$$

which would be violated if $\delta^{0}$ equaled or exceeded $2 / h$.

The second inequality in (30) implies both the second inequality of (31) and $\delta^{1}<2 / h$, so that $w_{2}^{1}$ is also given by (24). Using (17) and (26), (30) thus implies

$$
c_{L}^{1}-c_{2}^{1}=\frac{b(1-\phi)}{8}\left[1-\left(\frac{\sigma-\phi}{1-\phi}\right)^{2}\right]\left[\left(\delta^{0}\right)^{2}-\left(\delta^{1}\right)^{2}\right] .
$$

This means that, using (19), (24), and (27), $n_{1}^{1}$ is given by

$$
\begin{aligned}
n_{1}^{1}= & \frac{\delta^{1}+c_{2}^{1}-c_{L}^{1}}{2}+\frac{b}{8}\left(\delta^{1}\right)^{2}=\frac{\delta^{1}}{2}+\frac{b}{8}\left(\delta^{1}\right)^{2} \\
& +\frac{b(1-\phi)}{16}\left[1-\left(\frac{\sigma-\phi}{1-\phi}\right)^{2}\right]\left[\left(\delta^{0}\right)^{2}-\left(\delta^{1}\right)^{2}\right] .
\end{aligned}
$$

This means that $(30)$ is equivalent to the condition that $0<n_{1}^{1}<1 / h$. When this condition holds, changes in $\sigma_{w}$ affect $n_{1}^{1}$. By contrast, $n_{1}^{1}$ simply remains equal to $1 / h$ (or 0 ) in response to local changes in $\sigma_{w}$ if the condition is strictly violated.

The analogous argument when $s_{1}$ equals zero, so that we use (16) to compute $\left(c_{L}^{0}-c_{2}^{0}\right)$, implies that, when (30) holds, second-period wages are given by (24),

$$
\begin{aligned}
n_{1}^{0}= & \frac{\delta^{0}+c_{2}^{0}-c_{L}^{0}}{2}+\frac{b}{8}\left(\delta^{0}\right)^{2}=\frac{\delta^{0}}{2} \\
& +\frac{b}{8}\left(\delta^{0}\right)^{2}+\frac{b \phi}{16}\left[1-\left(\frac{\sigma-\phi}{1-\phi}\right)^{2}\right]\left[\left(\delta^{1}\right)^{2}-\left(\delta^{0}\right)^{2}\right],
\end{aligned}
$$

which, given (30) implies that $n_{0}^{1}$ is smaller than $1 / h$ as well. Thus, assuming the expression in (A2) is strictly positive, this cutoff also changes with 
$\sigma_{w}$. When both cutoffs change according to (23), replacing $f$ by $h$ and $f^{\prime}$ by zero (29) becomes

$$
\frac{d \Omega_{1}}{d \sigma_{w}}=\frac{\phi h\left(\sigma_{w}-\phi\right)}{1-\phi}\left(c_{2}^{1}-c_{2}^{0}\right)\left[\left(\delta^{0}-n_{1}^{0}\right)-\left(\delta^{1}-n_{1}^{1}\right)\right] .
$$

Using (A1) and (A2), the term in square brackets is

$$
\frac{b}{16}\left[\left(\delta^{1}\right)^{2}-\left(\delta^{0}\right)^{2}\right]\left\{1+\frac{1}{2}\left[1-\left(\frac{\sigma-\phi}{1-\phi}\right)^{2}\right]\right\}-\frac{v}{2}\left(r^{1}-r^{0}\right) .
$$

When $r^{1}$ equals $r^{0}$, this is zero. The derivative of this expression with respect to $r^{1}$ is

$$
\begin{aligned}
v\left(\frac{b}{4}\left(\delta^{1}\right)\right. & \left.\left\{1+\frac{1}{2}\left[1-\left(\frac{\sigma-\phi}{1-\phi}\right)^{2}\right]\right\}-\frac{1}{2}\right) \\
& \leq v\left[\frac{3 b}{8}\left(\delta^{1}\right)-\frac{1}{2}\right] \\
& <v\left[\frac{6 b}{8 b}-\frac{1}{2}\right]<0 .
\end{aligned}
$$

where the first inequality follows from the fact that $\sigma$ is no smaller than $\phi$, while the second follows from the fact that $\delta^{1}$ is smaller than $2 / h$. Thus $d \Omega_{1} / d \sigma_{w}$ is negative when (30) holds. Note that, if the expression in (A2) is negative, all employees with $s_{1}$ equal to zero leave their first employer, so that $n_{1}^{\circ}$ does not vary with $\sigma_{w}$. Thus, a fortiori, increases in $\sigma_{w}$ lower $\Omega_{1}$.

Now consider the case where (30) fails while (31) holds. Since it is no longer certain that $\delta^{1}<2 / h$ (though this inequality is true when $\delta^{1}$ is replaced by $\left.\delta^{\circ}\right),(16)$ and (26) now imply that

$$
c_{L}^{0}-c_{2}^{0}=\frac{b \phi}{8}\left[1-\left(\frac{\sigma-\phi}{1-\phi}\right)^{2}\right]\left\{\min \left[\frac{4}{b^{2}},\left(\delta^{1}\right)^{2}\right]-\left(\delta^{0}\right)^{2}\right\} .
$$

Equations (19) and (27) thus imply that

$$
n_{1}^{\circ}=\frac{\delta^{0}}{2}+\frac{b}{8}\left(\delta^{0}\right)^{2}+\frac{b \phi}{16}\left[1-\left(\frac{\sigma-\phi}{1-\phi}\right)^{2}\right]\left\{\min \left[\frac{4}{b^{2}},\left(\delta^{1}\right)^{2}\right]-\left(\delta^{1}\right)^{2}\right\} .
$$

Thus, (31) ensures that $0<n_{1}^{0}<1 / h$, so that changes in $\sigma_{w}$ still affect $n_{1}^{\circ}$. Therefore,

$$
\frac{d \Omega_{1}}{d \sigma_{w}}=\frac{\phi h\left(\sigma_{w}-\phi\right)}{1-\phi}\left(c_{2}^{1}-c_{2}^{0}\right)\left(\delta^{0}-n_{1}^{0}\right) .
$$


Using (A2), the right-hand term in parentheses is

$$
\frac{\delta^{0}}{2}\left(1-\delta^{0} \frac{b}{4}\right)+\frac{c_{L}^{0}-c_{2}^{0}}{2} .
$$

This is greater than zero because the last term is positive, while $\delta^{0}$ is less than $2 / h$. This establishes that $\Omega_{1}$ rises with $\sigma_{w}$ when (30) fails while (31) holds. A small variant on the above calculations demonstrates that neither $n_{1}^{\circ}$ nor $n_{1}^{1}$ varies with $\sigma_{w}$ when both the second inequality in (30) and the second inequality in (31) fail. Q.E.D.

\section{Proof of Proposition 8}

From Bayes rule,

$$
\begin{aligned}
P\left(r=1 \mid s_{2}=0, s_{1}=1\right) & =\frac{P\left(r=1, s_{2}=0 \mid s_{1}=1\right)}{P\left(s_{2}=0 \mid s_{1}=1\right)} \\
& =\frac{P\left(s_{2}=0 \mid r=1, s_{1}=1\right) P\left(r=1 \mid s_{1}=1\right)}{P\left(s_{2}=0 \mid s_{1}=1\right)} \\
& =\frac{\sigma(1-\sigma)(1-\phi)}{(1-\phi)^{2}-(\sigma-\phi)^{2}}=\frac{\sigma(1-\phi)}{1+\sigma-2 \phi} .
\end{aligned}
$$

Thus, given (5) and (24),

$$
\begin{aligned}
\Delta & =q_{S}+v P\left(r=1 \mid s_{1}=1, s_{2}=0\right)-\frac{w_{2}^{1}-w_{2}^{0}}{2} \\
& \geq \frac{q_{S}-q_{N}}{2}+v\left[\frac{\sigma(1-\phi)}{1+\sigma-2 \phi}-\frac{\sigma}{4}-\frac{\phi(1-\sigma)}{4(1-\phi)}\right] .
\end{aligned}
$$

A strict inequality obtains if the second boundary condition in (3) is violated, because this would mean that smaller wages are sufficient to keep workers with probability one. Thus

$$
\frac{q_{s}-q_{N}+v \frac{(1-\sigma) \phi}{1-\phi}}{2 v}+\frac{\sigma(1-\phi)}{1+\sigma-2 \phi}-\frac{\sigma}{4}-\frac{3(1-\sigma) \phi}{4(1-\phi)}>0 \Rightarrow \Delta=0 .
$$

Multiplying through by $(1+\sigma-2 \phi)(1-\phi)$ and manipulating, this condition becomes

$$
\begin{aligned}
& \left.2\left[(1-\phi)\left(q_{s}-q_{N}\right)(1+\sigma-2 \phi) / v+(1-\sigma) \phi\right)+(1-\sigma) \phi(\sigma-\phi)\right] \\
& \quad+(\sigma-\phi)[3-6 \phi+\sigma(4 \phi-1)]>0 .
\end{aligned}
$$

Because $\sigma$ must exceed $\phi$ and the zeros of the equation $4 \phi^{2}-7 \phi+3=$ 0 occur at $3 / 4$ and 1 , the second term in square brackets is positive if $\phi$ is less than $3 / 4$. Since (5) ensures that the first term in square brackets (which is proportional to the first term in [A5]) is nonnegative, this is 
sufficient to imply that $\Delta>0$. The second term in square brackets can also be written as

$$
(\sigma-\phi)(4 \phi-1)-4(1-\phi)(3 / 4-\phi) .
$$

It is thus also positive when $\phi>3 / 4$ as long as iii is satisfied. Moreover, for $\phi>3 / 4$, the ratio $4(1-\phi)(3 / 4-\phi) /(4 \phi-1)$ reaches a maximum of .0253 when $\phi$ equals .862 . The last inequality above can also be written as

$$
\begin{aligned}
& 2[(1-\phi)(1+\sigma-2 \phi)]\left[\left(q_{S}-q_{N}\right)+\frac{v(1-\sigma) \phi}{1+\sigma-2 \phi}\right] \\
& \quad+(\sigma-\phi)[3-4 \phi+\sigma(2 \phi-1)]>0 .
\end{aligned}
$$

Given that the zeros of the equation $2 \phi^{2}-5 \phi+3=0$ occur at 1 and at 1.5 whereas $\phi$ must be less than one, the third term in square brackets must be nonnegative. Therefore, it is sufficient for $\Delta>0$ that the second term in square brackets be positive.

When all three conditions are violated while $b$ is also small enough that (25) holds for both types of employees, $d \Omega_{1} / d \sigma_{w}<0$. Q.E.D.

\section{References}

Abowd, John; Kramarz, Francis; and Margolis, David. "High Wage Workers and High Wage Firms." Econometrica 67 (March 1999): 251-333.

Abraham, Katharine G., and Farber, Henry S. "Job Duration, Seniority, and Earnings.” American Economic Review 77 (June 1987): 278-97.

Acemoglu, Daron, and Pischke, Jörn-Steffen. "Why Do Firms Train? Theory and Evidence.” Working Paper no. 96-7. Cambridge, MA: MIT, Department of Economics, February 1996.

Akerlof, George A. "Labor Contracts as Partial Gift Exchange." Quarterly Journal of Economics 97 (November 1982): 54-69.

Atkinson, Anthony B.; Rainwater, Lee; and Smeedling, Timothy. "Income Distribution in European Countries." In Incomes and the Welfare State: Essays on Britain and Europe, edited by Anthony B. Atkinson. Cambridge: Cambridge University Press, 1995.

Bernstein, Jared, and Mishel, Lawrence. "Has Inequality Stopped Growing?” Montbly Labor Review 120 (December 1997): 3-16.

Bolton, Patrick, and Harris, Christopher. "Strategic Experimentation." Econometrica 67 (March 1999): 349-74.

Burgess, Simon. "The Reallocation of Labour: An International Comparison Using Job Tenure Data." Performance Discussion Paper no. 416. London: London School of Economics, Center for Economic Performance Discussion, March 1999.

Burgess, Simon, and Rees, Hedley. "A Disaggregated Analysis of the Evolution of Job Tenure in Britain, 1975-1993." British Journal of Industrial Relations 36 (December 1998): 629-55. 
Deininger, Klaus, and Squire, Lyn. "A New Data Set Measuring Income Inequality.” World Economic Review 10 (September 1996): 565-91.

Diebold, Francis X.; Neumark, David; and Polsky, Daniel. "Comment on Kenneth Swinnerton and Howard Wial's 'Is Job Stability Declining in the U.S. Economy?'” Industrial and Labor Relations Review 49 (January 1996): 348-52.

Evans, Geoffrey. "Class Conflict and Inequality." In International Social Attitudes: The Tenth BSA Report, edited by Robert Jowell, Lindsay Brooks, and Lizanne Dowds. Brookfield, VT: Dartmouth, 1993.

Farber, Henry, "Are Lifetime Jobs Disappearing? Job Duration in the United States, 1973-1993.” In Labor Statistics Measurement Issues, Studies in Income and Wealth, vol. 60, edited by John Haltiwanger, Marilyn E. Manser, and Robert Topel. Chicago: University of Chicago Press, 1998.

Feagin, Joe R. Subordinating the Poor. Englewood Cliffs, NJ: PrenticeHall, 1975.

Hochschild, Jennifer. What's Fair? American Beliefs about Distributive Justice. Cambridge, MA: Harvard University Press, 1981.

Kluegel, James, and Smith, Eliot R. Beliefs about Inequality. New York: De Gruyter, 1986.

McClosky, Herbert, and Zaller, John. The American Ethos. Cambridge, MA: Harvard University Press, 1984.

McLaughlin, Kenneth J. "A Theory of Quits and Layoffs with Efficient Turnover." Journal of Political Economy 99 (February 1991): 1-29.

Moss, David A. Unemployment in France: "Priority Number One." Case 9-795-064. Boston: Harvard Business School Publishing, 1995.

Piketty, Thomas. "Social Mobility and Redistributive Politics." Quarterly Journal of Economics 110 ( August 1995): 551-84.

Swinnerton, K., and Wial, H. "Is Job Stability Declining in the U.S. Economy? Reply to Diebold, Neumark and Polsky." Industrial and Labor Relations Review 49 (January 1996): 352-55.

Uchitelle, Louis. "Insecurity Forever." New York Times, November 20, 1994. 